\title{
Synthesis and Characterization of Water-Soluble and Photostable L-DOPA Dendrimers
}

\author{
Shengzhuang Tang, Lynda J. Martinez, Ajit Sharma and Minghui Chai*
}

Department of Chemistry, Central Michigan University, Mt. Pleasant, MI 48859

To whom correspondence should be addressed: minghui.chai@cmich.edu

* Corresponding author. Address: Department of Chemistry, Dow 342, Central Michigan University, Mt. Pleasant, MI 48859. Tel: 1-989-774-3955. Fax: 1-989-774-3883. E-mail: chai1m@cmich.edu. 
Table of Contents:

1. Detailed Experimental Procedures................................ S3-S20

2. Gel electrophoresis Measurements ................................... S21

3. NMR Spectra Important Intermediates and Final Products .............. S22-S33

4. UV-Vis Data on the Photostability of L-DOPA and G3 L-DOPA Dendrimer . S34

5. HPLC Chromatograms of L-DOPA Dendrimers G0-G3 …............... S35

6. NMR and HPLC Studies on the Degradation of L-DOPA Dendrimers ... S36-S38 


\section{Detailed Experimental Procedures :}

General procedures: All reactions were carried out under a nitrogen atmosphere with anhydrous and freshly distilled analytical grade solvents unless otherwise noted or unless aqueous solvents were used. Anhydrous dichloromethane (DCM) and pyridine were prepared by distillation from calcium hydride under a nitrogen atmosphere. Acetone was prepared by distillation under a nitrogen atmosphere. Dry tetrahydrofuran (THF) and methanol $(\mathrm{MeOH})$ were purchased from Aldrich. All chemicals were purchased from Aldrich and Fisher as highest purity grade and used without further purification. 3,4Dihydroxy-L-Phenylalanine (L-DOPA) was obtained at the highest commercial quality from Aldrich. 4-(dimethylamino)-pyridinium p-toluenesulfonate (DPTS) was synthesized using reported procedure. Reactions were monitored by thin-layer chromatography (TLC) performed on silica gel $\mathrm{UV}_{254}$ flexible plates. Column chromatography was carried out using silica gel (60-100 mesh). NMR spectra were recorded on Varian Mercury $300 \mathrm{MHz}$ NMR spectrometer at a constant temperature of $25^{\circ} \mathrm{C} .{ }^{1} \mathrm{H}$ Chemical shifts $(\delta)$ were calibrated using $\mathrm{CDCl}_{3}(\delta=7.26 \mathrm{ppm})$ and $\mathrm{CD}_{3} \mathrm{OD}$ (central peak, $\left.\delta=3.31 \mathrm{ppm}\right)$ as an internal reference; ${ }^{13} \mathrm{C}$ Chemical shifts value $(\delta)$ were referenced to $\mathrm{CDCl}_{3}$ (central peak, $\delta=77.00 \mathrm{ppm})$ and $\mathrm{CD}_{3} \mathrm{OD}$ (central peak, $\left.\delta=49.15 \mathrm{ppm}\right)$ as the internal standard. Standard abbreviations indicating multiplicity were used as follows: $\mathrm{s}=$ singlet, $\mathrm{d}=$ doublet, $\mathrm{t}=$ triplet, $\mathrm{m}=$ multiplet, $\mathrm{b}=$ broad. Mass spectra were measured on a Bruker MALDI-TOF-MS spectrometer. Yields refer to chromatographically and spectroscopically $\left({ }^{1} \mathrm{H}\right.$ NMR $)$ homogeneous materials. DCC $=$ dicyclohexylcarbodiimide, $\mathrm{DCU}=1,3$-dicyclohexylurea, Boc = tert-butyloxycarbonyl, $\mathrm{Bn}=$ benzyl . 


\section{Experimental details and spectral characterization data for compounds 2 - 17:}

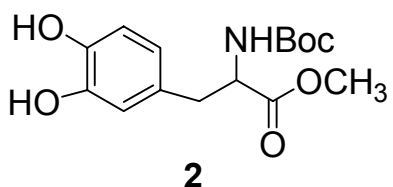

2

HO-DOPA-NH-Boc-COOMe 2: $80 \mathrm{~mL}$ methanol was cooled

to $0^{\circ} \mathrm{C}$ and thiony chloride $(3.56 \mathrm{~mL}, 48.8 \mathrm{mmol})$ was added dropwise. The solution was allowed to warm to room

temperature, and L- DOPA 1 (8.000 g, $40.4 \mathrm{mmol})$ was added wisely. The solution was stirred for $18 \mathrm{~h}$ at room temperature and concentrated to give a yellow powder. The resulting mixture was dissolved in THF $(60 \mathrm{~mL})$ and saturated aqueous $\mathrm{NaHCO}_{3}(60 \mathrm{~mL})$ was added. The resulting solution was cooled at $0^{\circ} \mathrm{C}$ and di-tertbutyl-dicarbonate $(1 \mathrm{M}$ in THF) (44.4 mL, $44.4 \mathrm{mmol}$ ) was added dropwise. The solution was allowed to warm to room temperature and stirred for $1 \mathrm{~h}$. The organic solvent was moved and the aqueous layer was extracted with ethyl acetate $(2 \times 60 \mathrm{~mL})$. The combined organic extracts were washed subsequently with water $(2 \times 60 \mathrm{~mL}), 5 \% \mathrm{HCl}(60 \mathrm{~mL})$, water $(60 \mathrm{~mL})$, and brine $(60 \mathrm{~mL})$. The resulting solution was dried over $\mathrm{MgSO}_{4}$, filtered and concentrated. Flash column chromatography (1:1 EtOAc/hexanes) afforded product 2 as a white solid (11.320 g, 90\%). ${ }^{1} \mathrm{H} \mathrm{NMR}\left(\mathrm{CDCl}_{3}\right) \delta^{1} \mathrm{H}(300 \mathrm{MHz}): 1.416\left(9 \mathrm{H}, \mathrm{s}, \mathrm{Boc}_{-} \mathrm{CH}_{3}\right), 2.962(2 \mathrm{H}, \mathrm{m}$, DOPA-CH $\left.\mathrm{CH}_{2}\right), 3.690\left(3 \mathrm{H}, \mathrm{s}, \mathrm{OCH}_{3}\right), 4.513(1 \mathrm{H}, \mathrm{m}, \mathrm{DOPA}-\mathrm{CH}), 5.175(1 \mathrm{H}, \mathrm{d}, J=5.1 \mathrm{~Hz}$, DOPA-NH), 6.526 (1H, d, $J=4.5 \mathrm{~Hz}, 6-\mathrm{ArH}), 6.651(1 \mathrm{H}, \mathrm{s}, 2-\mathrm{ArH}), 6.752(1 \mathrm{H}, \mathrm{d}, J=$ 5.1 Hz, 5-ArH); ${ }^{13} \mathrm{C}$ NMR $\left(\mathrm{CDCl}_{3}\right) \delta^{13} \mathrm{C}(75 \mathrm{MHz}): 27.396\left(\mathrm{Boc}^{-\mathrm{CH}_{3}}\right), 37.750$ (DOPA$\left.\mathrm{CH}_{2}\right), 52.316\left(\mathrm{OCH}_{3}\right), 54.552$ (DOPA-CH), 80.289 (Boc-C), 115.289 (2-ArC), 116.128 (6-ArC), 121.538 (5-ArC), 128.413 (1-ArC), 143.788 (3-ArC), 146.733 (4-ArC), 155.386 (Boc-CO), 172.623 (DOPA-CO); MALDI-TOF-MS found [M+Na] $]^{+} 334.0 ; \mathrm{C}_{15} \mathrm{H}_{21} \mathrm{NO}_{6}$ requires 311.3. 


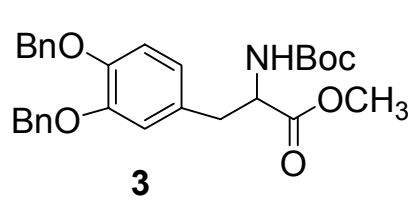

BnO-DOPA-NHBoc-COOMe 3: To HO-DOPA-NHBocCOOMe $2(9.432 \mathrm{~g}, 30.3 \mathrm{mmol})$ in acetone $(90 \mathrm{~mL})$ were added $\mathrm{K}_{2} \mathrm{CO}_{3}(12.442 \mathrm{~g}, 84.1 \mathrm{mmol}$ ) and $\mathrm{NaI}(540 \mathrm{mg}, 3.9$ mmol) and stirred for $1 \mathrm{~h}$. Benzyl bromide (10.1 mL, $81 \mathrm{mmol})$ was added. The solution was heated to reflux for $18 \mathrm{~h}$ and then cooled and concentrated. This sediment was dissolved in $\mathrm{CH}_{2} \mathrm{Cl}_{2}(100 \mathrm{~mL})$. The solution was washed with water $(2 \times 100 \mathrm{~mL}), 5 \% \mathrm{HCl}$ $(100 \mathrm{~mL})$, water $(100 \mathrm{~mL})$, brine $(100 \mathrm{~mL})$, dried over $\mathrm{MgSO}_{4}$, filtered, and concentrated. Flash column chromatography $\left(\mathrm{CH}_{2} \mathrm{Cl}_{2}\right.$ and then $3 \% \mathrm{CH}_{3} \mathrm{OH}$ in $\left.\mathrm{CH}_{2} \mathrm{Cl}_{2}\right)$ afforded product 3, a white solid (11.767 g, 79\%). ${ }^{1} \mathrm{H}$ NMR $\left(\mathrm{CDCl}_{3}\right) \delta^{\prime} \mathrm{H}(300 \mathrm{MHz}): 1.424$ (9H, s, Boc$\left.\mathrm{CH}_{3}\right), 2.976\left(2 \mathrm{H}, \mathrm{m}, \mathrm{DOPA}-\mathrm{CH}_{2}\right), 3.643\left(3 \mathrm{H}, \mathrm{s}, \mathrm{OCH}_{3}\right), 4.523(1 \mathrm{H}, \mathrm{m}, \mathrm{DOPA}-\mathrm{CH})$, $4.940\left(1 \mathrm{H}, \mathrm{d}, J=7.8 \mathrm{~Hz}\right.$, DOPA-NH), 5.121 and $5.126\left(4 \mathrm{H}, \mathrm{s}, 2 \mathrm{Benzyl}-\mathrm{CH}_{2}\right), 6.639(1 \mathrm{H}$, d-d, $J=8.2$ and $1.9 \mathrm{~Hz}, 6-\mathrm{ArH}), 6.731(1 \mathrm{H}, \mathrm{d}, J=2.1 \mathrm{~Hz}, 2-\mathrm{ArH}), 6.858(1 \mathrm{H}, \mathrm{d}, J=8.1$ $\mathrm{Hz}, 5-\mathrm{ArH})$, 7.296-7.460 (10H, m, Benzyl-ArH); ${ }^{13} \mathrm{C} \mathrm{NMR}\left(\mathrm{CDCl}_{3}\right) \delta^{{ }^{13} \mathrm{C}}(75 \mathrm{MHz})$ : $28.296\left(\mathrm{Boc}^{\left.-\mathrm{CH}_{3}\right)}\right), 37.765\left(\mathrm{DOPA}-\mathrm{CH}_{2}\right), 52.148\left(\mathrm{OCH}_{3}\right), 54.376$ (DOPA-CH), 71.270 and 71.300 (2Benzyl- $\mathrm{CH}_{2}$ ), 79.915 (Boc-C), 115.060 (2-ArC) , 116.128 (6-ArC), 122.263 (5-ArC), 127.245 and 127.306 (2-C, 2'-C, Benzyl), 127.749 and 127.802 (3-C, 3'-C, Benzyl), 128.443 and128.474 (4-C, 4'-C , Benzyl), 129.191 (1-ArC), 137.150 and 137.272 (1-, 1'-C, Benzyl), 148.061 (3-ArC), 148.862 (4-ArC), 155.050 (Boc-CO), 172.325 (DOPA-CO). MALDI-TOF-MS found $[\mathrm{M}+\mathrm{Na}]^{+} 514.2$ and $[\mathrm{M}+\mathrm{K}]^{+} 550.6$; $\mathrm{C}_{29} \mathrm{H}_{33} \mathrm{NO}_{6}$ requires 491.6.

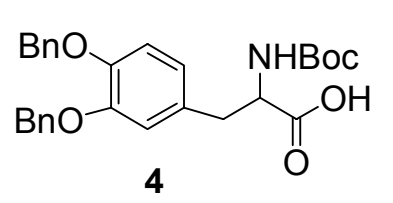

BnO-DOPA-NHBoc-COOH 4: To a solution of BnODOPA-NHBoc-COOMe $3(10.560 \mathrm{~g}, 21.48 \mathrm{mmol})$ in 1:1 THF/Methanol (60 mL) was added aqueous $\mathrm{NaOH}(3 \mathrm{M}, 30$ 
$\mathrm{mL}$ ) dropwise. The solution was stirred at room temperature for $6 \mathrm{~h}$. The solution was then acidified to $\mathrm{pH}=3$ with aqueous $\mathrm{HCl}(5 \%)$ and extracted with $\mathrm{CH}_{2} \mathrm{Cl}_{2}(3 \times 60 \mathrm{~mL})$. The combined organic extracts were washed with water $(180 \mathrm{~mL})$, brine $(180 \mathrm{~mL})$, dried over $\mathrm{MgSO}_{4}$, filtered, and concentrated. Flash column chromatography (2:1 EtOAc /hexanes) afforded product 4 as a white solid (9.539 g, 93\%). ${ }^{1} \mathrm{H}$ NMR $\left(\mathrm{CDCl}_{3}\right) \delta^{1} \mathrm{H}(300$ MHz): 1.419 (9H, s, Boc- $\left.\mathrm{CH}_{3}\right), 3.025\left(2 \mathrm{H}, \mathrm{m}, \mathrm{DOPA}-\mathrm{CH}_{2}\right), 4.505(1 \mathrm{H}, \mathrm{m}$, DOPA-CH), $4.874\left(1 \mathrm{H}, \mathrm{d}, J=6.9 \mathrm{~Hz}\right.$, DOPA-NH), $5.121\left(4 \mathrm{H}, \mathrm{s}, 2\right.$ Benzyl-CH$\left._{2}\right), 6.678(1 \mathrm{H}, \mathrm{d}-\mathrm{d}, J=$ 8.1 and $1.8 \mathrm{~Hz}, 6-\mathrm{ArH}), 6.756(1 \mathrm{H}, \mathrm{d}, J=2.1 \mathrm{~Hz}, 2-\mathrm{ArH}), 6.854(1 \mathrm{H}, \mathrm{d}, J=8.4 \mathrm{~Hz}, 5-$ ArH), 7.294-7.450 (10H, m, BnO-ArH); ${ }^{13} \mathrm{C}$ NMR $\left(\mathrm{CDCl}_{3}\right) \delta^{13} \mathrm{C}(75 \mathrm{MHz}): 28.273$ (Boc$\mathrm{CH}_{3}$ ), 37.101 (DOPA-CH$), 54.254$ (DOPA-CH), 71.239 (Benzyl- $\mathrm{CH}_{2}$ ), 80.441 (Boc-C), 115.014 (2-ArC), 116.227 (6-ArC), 122.309 (5-ArC), 127.126 and 127.368 (2-C, 2'-C, Benzyl), 127.772 (3-C, 3'-C, Benzyl), 128.466 and128.504 (4-C, 4'-C , Benzyl), 128.871 (1-ArC), 137.241 (1-C, 1'-C, Benzyl), 148.152 (3-ArC), 148.770 (4-ArC), 155.508 (Boc-CO), 174.843 (DOPA-CO). MALDI-TOF-MS found $[\mathrm{M}+\mathrm{Na}]^{+} 500.2$ and $[\mathrm{M}+\mathrm{K}]^{+}$522.2; $\mathrm{C}_{28} \mathrm{H}_{31} \mathrm{NO}_{6}$ requires 477.5.

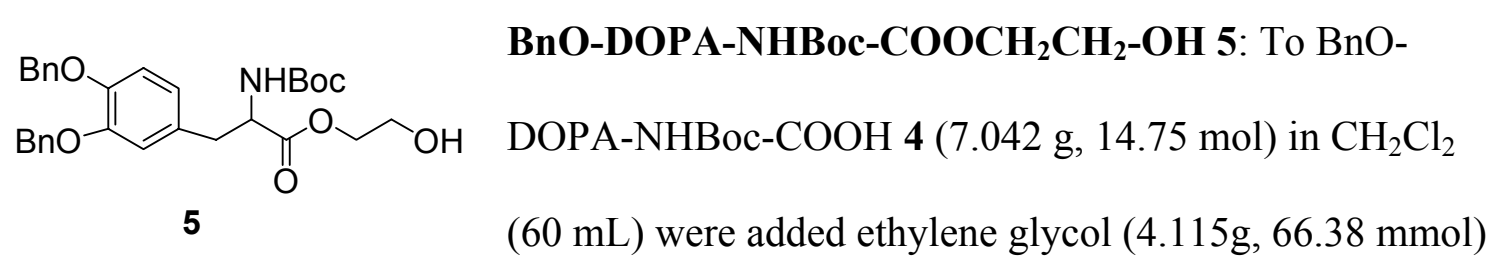

and DPTS (860 mg, $4.4 \mathrm{mmol})$. The mixture was cooled over ice and DCC (1 M in $\left.\mathrm{CH}_{2} \mathrm{Cl}_{2}\right)(16.22 \mathrm{~mL}, 16.22 \mathrm{mmol})$ was added dropwise. The reaction mixture was allowed to warm to room temperature and stirred for $6 \mathrm{~h}$. The reaction was quenched with water (60 mL).The solid (DCU) was filtered off and washed with cool $\mathrm{CH}_{2} \mathrm{Cl}_{2}(5 \mathrm{~mL})$. The organic layer was separated and washed with water $(60 \mathrm{~mL})$, brine $(60 \mathrm{~mL})$, dried over 
$\mathrm{MgSO}_{4}$, filtered and then concentrated. The sediment was dissolved in 1:1

EtOAc/hexanes $(100 \mathrm{~mL})$ to precipitate extra DCU. The solution was filtered and concentrated. A flash chromatography (1:2 to 1:1 EtOAc/hexane) afforded product 5 as a colorless solid (6.616 g, 86\%). ${ }^{1} \mathrm{H}$ NMR $\left(\mathrm{CDCl}_{3}\right) \delta^{\prime} \mathrm{H}(300 \mathrm{MHz}): 1.425$ (9H, s, Boc- $\left.\mathrm{CH}_{3}\right)$, $2.990\left(2 \mathrm{H}, \mathrm{d}, J=5.7 \mathrm{~Hz}\right.$, DOPA- $\left.\mathrm{CH}_{2}\right), 3.869-4.073\left(4 \mathrm{H}, \mathrm{m}, \mathrm{OCH}_{2} \mathrm{CH}_{2} \mathrm{O}\right), 4.444(1 \mathrm{H}, \mathrm{m}$, DOPA-CH), 4.937 (1H, d, $J=7.2 \mathrm{~Hz}$, DOPA-NH), 5.131 (4H, s, 2Benzyl- $\left.\mathrm{CH}_{2}\right), 6.674$ $(1 \mathrm{H}, \mathrm{d}-\mathrm{d}, J=7.2$ and $0.9 \mathrm{~Hz}, 6-\mathrm{ArH}), 6.779(1 \mathrm{H}, \mathrm{d}, J=1.8 \mathrm{~Hz}, 2-\mathrm{ArH}), 6.870(1 \mathrm{H}, \mathrm{d}, J=$ 8.1 Hz, 5-ArH), 7.299-7.462 (10H, m, Benzyl-ArH); ${ }^{13} \mathrm{C}$ NMR $\left(\mathrm{CDCl}_{3}\right) \delta^{{ }^{13} \mathrm{C}}(75 \mathrm{MHz})$ : $28.281\left(\mathrm{Boc}^{\left.-\mathrm{CH}_{3}\right)}, 37.521\right.$ (DOPA-CH$), 54.758$ (DOPA-CH), 61.277 and 67.282 $\left(\mathrm{OCH}_{2} \mathrm{CH}_{2} \mathrm{O}\right.$ ), 71.239 and 71.346 (2Benzyl - $\left.\mathrm{CH}_{2}\right), 80.281$ (Boc-C), 115.113 (2-ArC), 116.082 (6-ArC), 122.171 (5-ArC), 127.245 and 127.337 (2-C, 2'-C, Benzyl), 127.772 and 127.833 (3-C, 3'-C, Benzyl), 128.459 and 128.482 ( 4-C, 4'-C , Benzyl), 129.077 (1ArC), 137.111 and 137.226 (1-C, 1'-C, Benzyl), 148.213 (3-ArC), 148.999 (4-ArC), 155.401 (Boc-CO), 171.967 (DOPA-CO). MALDI-TOF-MS found [M+Na] $]^{+}$544.2; $\mathrm{C}_{30} \mathrm{H}_{35} \mathrm{NO}_{7}$ requires 521.6.

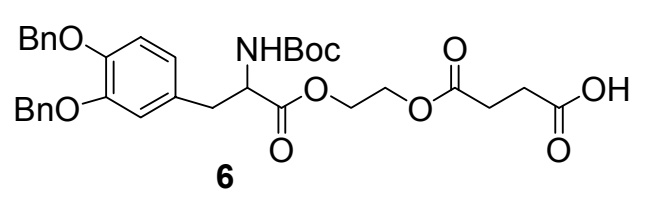

\section{BnO-DOPA-NHBoc- $\mathrm{COOCH}_{2} \mathrm{CH}_{2} \mathrm{OOCCH}_{2} \mathrm{CH}_{2} \mathrm{COOH}$ (the} building block) 6: To BnO-DOPA-NHBoc$\mathrm{COOCH}_{2} \mathrm{CH}_{2}-\mathrm{OH} 5(5.865 \mathrm{~g}, 11.24 \mathrm{mmol})$ in pyridine $(30 \mathrm{~mL})$ was added a solution of succinic anhydride $(1.69 \mathrm{~g}, 16.9 \mathrm{mmol})$ in pyridine $(30 \mathrm{~mL})$. The resulting reaction solution was stirred at room temperature for $18 \mathrm{~h}$ and concentrated. This material was dissolved in $\mathrm{CH}_{2} \mathrm{Cl}_{2}(60 \mathrm{~mL})$. The solution was washed with saturated aqueous $\mathrm{KHSO}_{4}$ $(60 \mathrm{~mL})$, water $(60 \mathrm{~mL})$, brine $(60 \mathrm{~mL})$, dried over $\mathrm{MgSO}_{4}$, filtered and then concentrated. 
A flash chromatography (1:1 EtOAc /hexane) afforded product 6, a white solid (4.753 g, 68\%). ${ }^{1} \mathrm{H}$ NMR $\left(\mathrm{CDCl}_{3}\right) \delta^{\prime} \mathrm{H}(300 \mathrm{MHz}): 1.417$ (9H, s, Boc- $\left.\mathrm{CH}_{3}\right), 2.628$ (4H, m, succ.$\left.\mathrm{CH}_{2}\right), 2.949-3.020\left(2 \mathrm{H}, \mathrm{m}\right.$, DOPA- $\left.\mathrm{CH}_{2}\right), 4.246-4.365\left(4 \mathrm{H}, \mathrm{m}, \mathrm{OCH}_{2} \mathrm{CH}_{2} \mathrm{O}\right), 4.597(1 \mathrm{H}$, m, DOPA-CH), 5.035 (1H, d, $J=4.8 \mathrm{~Hz}$, DOPA-NH), 5.123 and 5.130 (4H, s, 2 Benzyl$\left.\mathrm{CH}_{2}\right), 6.664(1 \mathrm{H}, \mathrm{d}, J=4.8 \mathrm{~Hz}, 6-\mathrm{ArH}), 6.772(1 \mathrm{H}, J=1.8,2-\mathrm{ArH}), 6.865(1 \mathrm{H}, \mathrm{d}, J=$ 4.5 Hz, 5-ArH), 7.294-7.453 (10H, m, 2Benzyl-ArH); ${ }^{13} \mathrm{C} \mathrm{NMR}\left(\mathrm{CDCl}_{3}\right) \delta^{{ }^{13} \mathrm{C}}(75 \mathrm{MHz})$ : $28.235\left(\right.$ Boc- $\left.^{-} \mathrm{CH}_{3}\right), 28.799$ and $29.074\left(\right.$ succ.- $\left.\mathrm{CH}_{2}\right), 37.574\left(\right.$ DOPA- $\left.\mathrm{CH}_{2}\right), 54.124$ (DOPA-CH), 61.831 and $62.724\left(\mathrm{OCH}_{2} \mathrm{CH}_{2} \mathrm{O}\right), 71.193$ and $71.206\left(2 \mathrm{Benzyl}-\mathrm{CH}_{2}\right)$, 80.563 (Boc-C), 114.999 (2-ArC), 116.090 (6-ArC), 122.209 (5-ArC), 127.223 and 127.314 (2-C, 2'-C, Benzyl), 127.726 and 127.764 (3-C, 3'-C, Benzyl), 128.413 ( 4-C, 4'C , Benzyl), 128.916 (1-ArC), 137.134 and 137.203 (1-C, 1'-C, Benzyl), 148.061 (3ArC), 148.862 (4-ArC), 155.607 (Boc-CO), 171.699 (DOPA-CO), 175.492 (succ.-CO); MALDI-TOF-MS found $[\mathrm{M}+\mathrm{Na}]^{+} 644.3,[\mathrm{M}+\mathrm{K}]^{+} 660.3 ; \mathrm{C}_{34} \mathrm{H}_{39} \mathrm{NO}_{10}$ requires 621.6 .

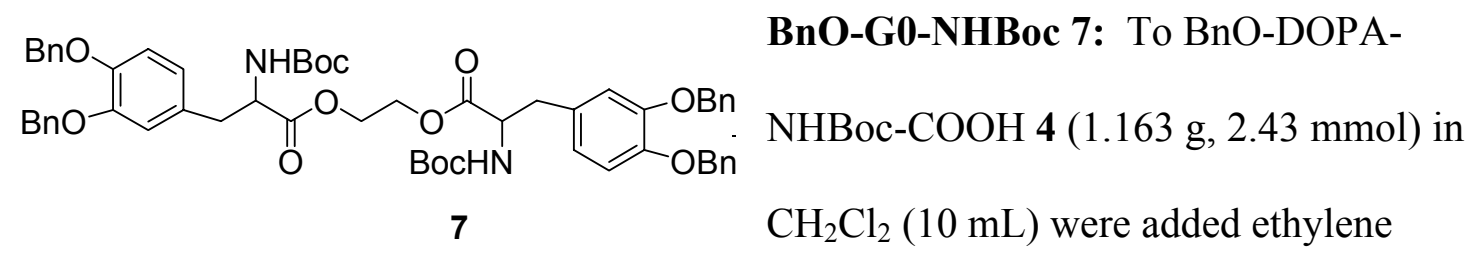

glycol (68 mg, $1.10 \mathrm{mmol})$ and DPTS (142 $\mathrm{mg}, 0.73 \mathrm{mmol})$. The mixture was cooled at $0^{\circ} \mathrm{C}$ and DCC $\left(1 \mathrm{M}\right.$ in $\left.\mathrm{CH}_{2} \mathrm{Cl}_{2}\right)(2.67 \mathrm{~mL}, 2.67 \mathrm{mmol})$ was added dropwise. The reaction mixture was allowed to warm to room temperature and stirred $16 \mathrm{~h}$. The reaction was quenched with water $(10 \mathrm{~mL})$. The solid (DCU) was filtered off and washed with cool $\mathrm{CH}_{2} \mathrm{Cl}_{2}(1 \mathrm{~mL})$. The organic layer was separated and washed with water $(10 \mathrm{~mL})$, brine (60 mL), dried over $\mathrm{MgSO}_{4}$, filtered and then concentrated. A flash chromatography ( $2 \%$ methanol in $\mathrm{CH}_{2} \mathrm{Cl}_{2}$ ) afforded product 7 as a colorless waxy solid (841 mg, $78 \%$ ). ${ }^{1} \mathrm{H}$ 
NMR $\left(\mathrm{CDCl}_{3}\right) \delta^{\prime} \mathrm{H}(300 \mathrm{MHz}): 1.401\left(18 \mathrm{H}, \mathrm{s}, \mathrm{Boc}_{-} \mathrm{CH}_{3}\right), 2.962\left(4 \mathrm{H}, \mathrm{m}, \mathrm{DOPA}-\mathrm{CH}_{2}\right)$, $4.166(4 \mathrm{H}, \mathrm{t}, J=3.3 \mathrm{~Hz}$, core-OCH $), 4.520(2 \mathrm{H}, \mathrm{m}, \mathrm{DOPA}-\mathrm{CH}), 4.950(2 \mathrm{H}, \mathrm{d}, J=8.1 \mathrm{~Hz}$, DOPA-NH), 5.089 and $5.099\left(8 \mathrm{H}, \mathrm{s}, 2 \mathrm{BnO}-\mathrm{CH}_{2}\right), 6.634(2 \mathrm{H}, \mathrm{d}-\mathrm{d}, J=8.2$ and $2.0 \mathrm{~Hz}, 6-$ ArH), $6.778(2 \mathrm{H}, \mathrm{d}, J=2.1 \mathrm{~Hz}, 2-\mathrm{ArH}), 6.842(2 \mathrm{H}, \mathrm{d}, J=8.4 \mathrm{~Hz}, 5-\mathrm{ArH}), 7.285-7.435$

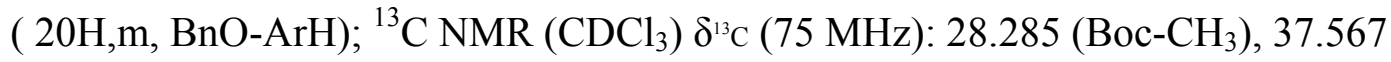
(DOPA-CH ${ }_{2}$ ), 54.361 (DOPA-CH), 62.563 (core- $\left.\mathrm{OCH}_{2}\right), 71.178$ and 71.206 (2 Benzyl$\mathrm{CH}_{2}$ ), 79.991 (Boc-C), 115.655 (2-ArC), 114.961 (6-ArC), 116.136 (5-ArC), 122.240 (1ArC), 127.253 and 127.322 (2-C, 2'-C, Benzyl), 127.749 and 127.787 (3-C, 3'-C, Benzyl), 128.443 and 128.459 ( 4-C, 4'-C , Benzyl), 128.985 (1-ArC), 137.134 and 137.233 (1-, 1'-C, Benzyl ), 148.122 (3-ArC), 148.839 (4-ArC), 155.065 (Boc-CO), 171.684 (DOPACO); MALDI-TOF-MS found $[\mathrm{M}+\mathrm{Na}]^{+} 1003.7$ and $[\mathrm{M}+\mathrm{K}]^{+}$1019.7; $\mathrm{C}_{58} \mathrm{H}_{64} \mathrm{~N}_{2} \mathrm{O}_{12}$ requires 981.1.

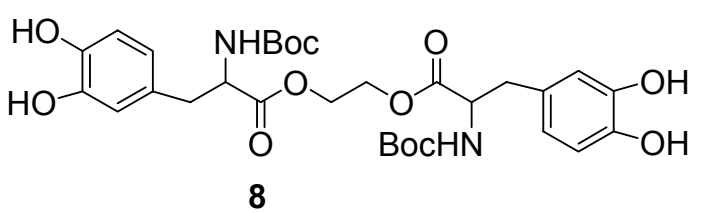

8
HO-G0-NHBoc 8: To a solution of BnOG0-NHBoc 7 (822 mg, $0.84 \mathrm{mmol})$ in THF $(10 \mathrm{~mL})$ was added $5 \%$ palladium on

charcoal $(150 \mathrm{mg})$. The suspension was then placed in a Parr tube on a hydrogenator, evacuated, flushed, and shaken under $50 \mathrm{psi}$ of $\mathrm{H}_{2}$ for $4 \mathrm{~h}$. The solution was filtered and concentrated. A flash chromatography (1:1 ethyl acetate/hexane) afforded HO-G0NHBoc 8 as a white solid (490 mg, 94\%). ${ }^{1} \mathrm{H}$ NMR $\left(\mathrm{CDCl}_{3}\right) \delta^{\prime} \mathrm{H}(300 \mathrm{MHz}): 1.429(18 \mathrm{H}$, s, Boc- $\left.\mathrm{CH}_{3}\right), 2.876\left(4 \mathrm{H}, \mathrm{m}, \mathrm{DOPA}-\mathrm{CH}_{2}\right), 4.131(4 \mathrm{H}, \mathrm{t}, J=3.3 \mathrm{~Hz}$, core-OCH$), 4.423$ (2H, m, DOPA-CH), $5.257(2 \mathrm{H}, \mathrm{d}, J=8.4 \mathrm{~Hz}, \mathrm{DOPA}-\mathrm{NH}), 6.489$ (2H, d-d, $J=8.1$ and $1.5 \mathrm{~Hz}, 6-\mathrm{ArH}), 6.654$ (2H, s, 2-ArH), 6.770 (2H, d, $J=8.1 \mathrm{~Hz}, 5-\mathrm{ArH}), 6.900$ ( 4H, b, $\mathrm{ArOH}) ;{ }^{13} \mathrm{C} \mathrm{NMR}\left(\mathrm{CDCl}_{3}\right) \delta^{13 \mathrm{C}}(75 \mathrm{MHz}): 28.265\left(\mathrm{Boc}^{\mathrm{C}} \mathrm{CH}_{3}\right), 38.101\left(\mathrm{DOPA}-\mathrm{CH}_{2}\right)$, 
54.697 (DOPA-CH), 62.602 (core-OCH ${ }_{2}$ ), 115.655 (2-ArC) , 116.052 (6-ArC), 121.393

(5-ArC), 127.772 (1-ArC), 143.216 (3-ArC), 144.246 (4-ArC), 155.867 (Boc-CO),

172.112 (DOPA-CO); MALDI-TOF-MS found [M+Na] $]^{+} 643.4$ and $[\mathrm{M}+\mathrm{K}]^{+}$659.4; $\mathrm{C}_{30} \mathrm{H}_{40} \mathrm{~N}_{2} \mathrm{O}_{12}$ requires 620.6.

BnO-G1-NHBoc 9: To HO-G0-NHBoc 8 (246 mg, $0.40 \mathrm{mmol})$ in $\mathrm{CH}_{2} \mathrm{Cl}_{2}(15 \mathrm{~mL})$ were added building block $6(1.184 \mathrm{~g}, 1.9 \mathrm{mmol})$ and DPTS (111 $\mathrm{mg}, 0.57 \mathrm{mmol})$. The mixture was cooled at $0^{\circ} \mathrm{C}$ and DCC $\left(1 \mathrm{M}\right.$ in $\left.\mathrm{CH}_{2} \mathrm{Cl}_{2}\right)(2.0 \mathrm{~mL}, 2.0 \mathrm{mmol})$ was added dropwise. The reaction mixture was allowed to warm to room temperature and stirred for $18 \mathrm{~h}$. The reaction was quenched with water $(10 \mathrm{~mL})$.The solid (DCU) was filtered off and washed with cool $\mathrm{CH}_{2} \mathrm{Cl}_{2}(1 \mathrm{~mL})$. The organic layer was separated and washed with water $(15 \mathrm{~mL})$, brine $(15 \mathrm{~mL})$, dried over $\mathrm{MgSO}_{4}$, filtered and then concentrated. The sediment was dissolved in 1:1 EtOAc/hexanes $(20 \mathrm{~mL})$ to precipitate extra DCU. The solution was filtered and concentrated. A flash chromatography (1:2 and then 1:1 EtOAc /hexane) afforded product 9 as a white waxy solid (922 mg, 76\%). ${ }^{1} \mathrm{H} \mathrm{NMR}\left(\mathrm{CDCl}_{3}\right) \delta^{1} \mathrm{H}$ (300 MHz): 1.386, and $1.405\left(54 \mathrm{H}, \mathrm{b}, \mathrm{Boc}-\mathrm{CH}_{3}\right), 2.668-2.712$ (8H, m, succ.- $\left.\mathrm{CH}_{2}\right)$, 2.826- $2.868\left(8 \mathrm{H}, \mathrm{m}\right.$, succ.- $\left.\mathrm{CH}_{2}\right), 2.935-3.037\left(12 \mathrm{H}, \mathrm{m}, \mathrm{DOPA}-\mathrm{CH}_{2}\right), 4.223(20 \mathrm{H}, \mathrm{b}$, $\left.\mathrm{OCH}_{2} \mathrm{CH}_{2} \mathrm{O}\right), 4.507-4.528$ (6H, m, DOPA-CH), 4.962 (6H, b, DOPA-NH), 5.098(16H, b, 8Benzyl- $\left.\mathrm{CH}_{2}\right), 6.638(4 \mathrm{H}, \mathrm{d}-\mathrm{d}, J=8.4$ and $J=2.1 \mathrm{~Hz}$, exterior 6-ArH), 6.743 (4H, d, $J=$ $1.2 \mathrm{~Hz}$, exterior 2-ArH), 6.844 (4H, d, $J=8.4 \mathrm{~Hz}$, exterior 5-ArH), 6.955-7.082 (6H, m, core-ArH), 7.281-7.434 ( 40H, m, 8Benzyl-ArH); ${ }^{13} \mathrm{C}$ NMR $\left(\mathrm{CDCl}_{3}\right) \delta^{13} \mathrm{C}(75 \mathrm{MHz})$ : 28.258 and 28.311 (core and exterior Boc- $\mathrm{CH}_{3}$ ), 28.624 (succ.- $\mathrm{CH}_{2}$ ), 37.620 (DOPA$\left.\mathrm{CH}_{2}\right), 54.353$ (DOPA - $\left.\mathrm{CH}\right), 62.258$, and $62.792\left(\mathrm{OCH}_{2} \mathrm{CH}_{2} \mathrm{O}\right), 71.277$ and 71.399 (Benzyl- $\mathrm{CH}_{2}$ ), 80.044 (Boc-C), 115.106, 116.349, 122.339, 123.369, 124.170, and 
129.138(Ar-CH), 127.276 and 127.352 (2-C, 2'-C, Benzyl), 127.764 and 127.818 (3-C, 3'-C, Benzyl), 128.451 and128.474 (4-C, 4'-C , Benzyl), 137.195 and 137.287 (1-, 1'-C, Benzyl), 141.003, 141.873, 148.1191, 148.915 (Ar-C), 155.065 (Boc-CO), 169.784, 169.853 (DOPA-CO), 169.784, 169.853, 171.364,171.860, 173.027 (succ.-CO); MALDITOF-MS found $[\mathrm{M}+\mathrm{Na}]^{+} 3059.8$ and $[\mathrm{M}+\mathrm{K}]^{+} 3075.8 ; \mathrm{C}_{166} \mathrm{H}_{188 \mathrm{~N}} 6 \mathrm{O} 48$ requires 3035.3 .

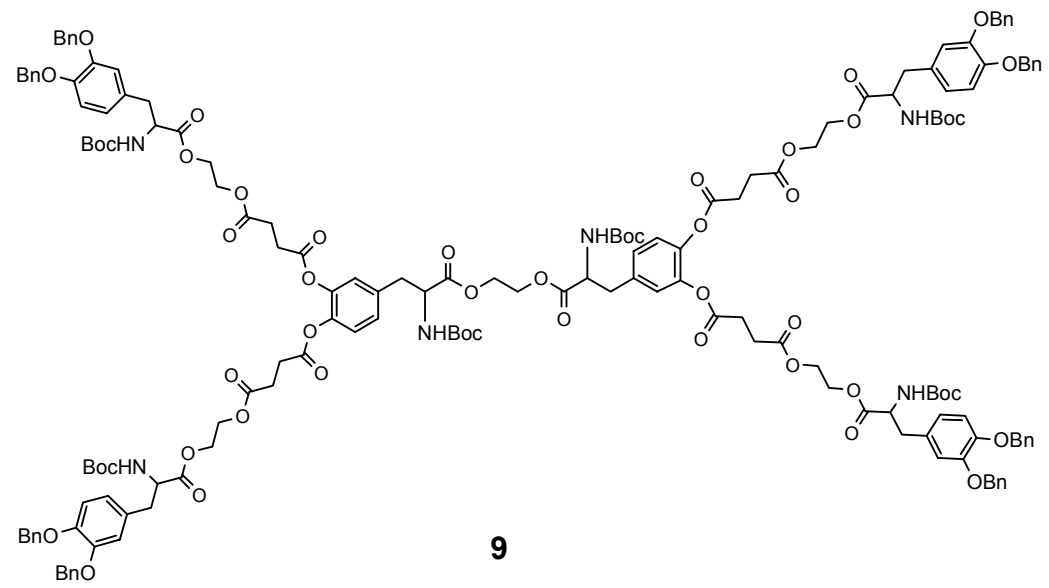

HO-G1-NHBoc 10: To a solution of BnO-G1-NHBoc 9 (505 mg, $0.17 \mathrm{mmol})$ in THF $(8 \mathrm{~mL})$ in a Parr tube was added $5 \%$ palladium on charcoal $(100 \mathrm{mg})$. The suspension was charged with hydrogen, evacuated, and then agitated under $50 \mathrm{psi}$ of $\mathrm{H}_{2}$ for $6 \mathrm{~h}$. The solid $(\mathrm{Pd} / \mathrm{C})$ was filtered off and washed with THF $(2 \mathrm{~mL})$. The filtrate was concentrated. A flash chromatography (2:1 ethyl acetate/hexane) afforded HO-G1-NHBoc 10 as a white solid (355 mg, 92\%). ${ }^{1} \mathrm{H}$ NMR $\left(\mathrm{CDCl}_{3}\right) \delta^{\prime} \mathrm{H}(300 \mathrm{MHz}): 1.381$ and $1.420(54 \mathrm{H}, \mathrm{b}$, Boc- $\mathrm{CH}_{3}$ ), 2.704-2.715 (8H, m, succ.- $\left.\mathrm{CH}_{2}\right), 2.879-2.890$ (8H, m, succ.- $\left.\mathrm{CH}_{2}\right), 2.944-3.011$ (12H, m, DOPA- $\left.\mathrm{CH}_{2}\right), 4.217\left(16 \mathrm{H}, \mathrm{m}\right.$, exterior $\left.\mathrm{OCH}_{2} \mathrm{CH}_{2} \mathrm{O}\right), 4.341(4 \mathrm{H}, \mathrm{m}$, core $\left.\mathrm{OCH}_{2} \mathrm{CH}_{2} \mathrm{O}\right), 4.490(4 \mathrm{H}, \mathrm{m}$, exterior DOPA- $\mathrm{CH}), 4.558(2 \mathrm{H}, \mathrm{m}$, core DOPA-CH), 5.078-5.128 (4H, m, exterior DOPA-NH), 5.297-5.332 (2H, m, core DOPA-NH), 6.484$6.498(4 \mathrm{H}, \mathrm{b}$, exterior 6-ArH), 6.580-6.606 (4H, b, exterior 2-ArH), 6.698-6.725 (4H, b, exterior 5-ArH), 6.952-7.065 (6H, b, core-ArH); ${ }^{13} \mathrm{C} \mathrm{NMR}\left(\mathrm{CDCl}_{3}\right) \delta^{{ }^{13} \mathrm{C}}(75 \mathrm{MHz})$ : 
28.189 and 28.281 (core and exterior Boc- $\mathrm{CH}_{3}$ ), $29.593\left(\right.$ succ.- $\mathrm{CH}_{2}$ ), 37.521 (DOPA$\left.\mathrm{CH}_{2}\right), 54.491$ (DOPA -CH), 62.419 and $62.831\left(\mathrm{OCH}_{2} \mathrm{CH}_{2} \mathrm{O}\right), 80.304$ (Boc-C), 115.312, 116.113, 121.340, 123.377, 124.178, 127.726, 135.196 (Ar-CH), 140.888, 141.720, 143.345, 144.063 (Ar-C), 155.439(Boc-CO), 170.730, 171.219(DOPA-CO), 172.020, 172.249 (succ.-CO); MALDI-TOF-MS found $\left.[\mathrm{M}+\mathrm{Na}]^{+}\right] 2337.2$ and $[\mathrm{M}+\mathrm{K}]^{+} 2353.2$; $\mathrm{C}_{110} \mathrm{H}_{140} \mathrm{~N}_{6} \mathrm{O} 48$ requires 2314.3.

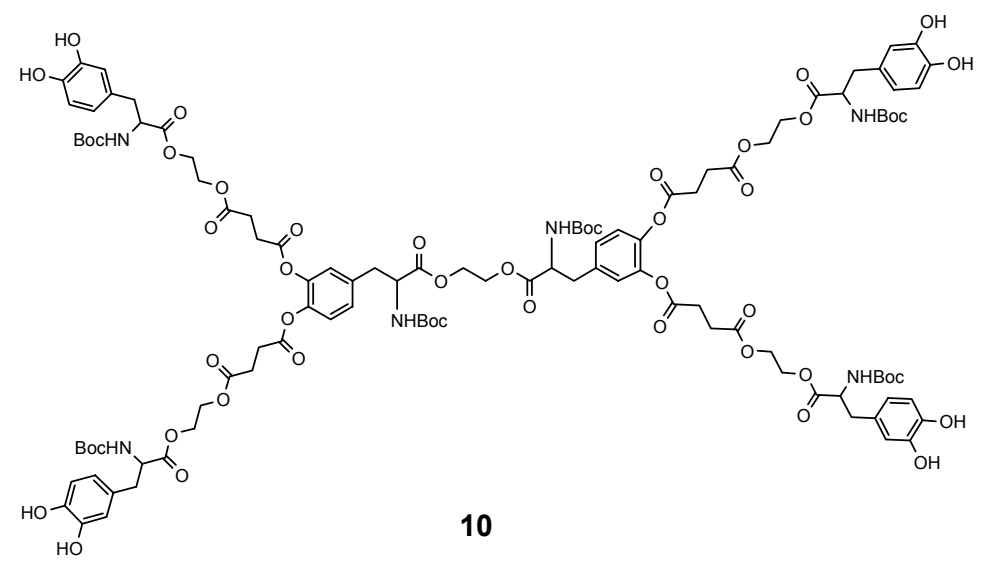

HO-G1-NH 21: To HO-G1-NHBoc $10(132 \mathrm{mg}, 0.057 \mathrm{mmol})$ a solution of $4 \mathrm{M} \mathrm{HCl}$ in dioxane $(2 \mathrm{~mL})$ was added. The reaction mixture was stirred at room temperature for 5 minutes. The chlorate of $\mathbf{1 1}$ was precipitated. The solvent and the remaining $\mathrm{HCl}$ were

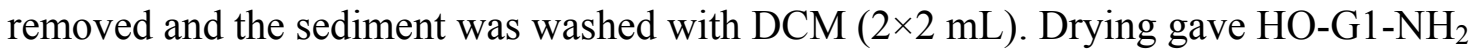
11 as a colorless powder $(96 \mathrm{mg}, 87 \%) .{ }^{1} \mathrm{H}$ NMR $\left(\mathrm{CD}_{3} \mathrm{OD}\right) \delta^{\prime} \mathrm{H}(300 \mathrm{MHz}): 2.646(8 \mathrm{H}, \mathrm{m}$, succ.- $\left.\mathrm{CH}_{2}\right), 2.830\left(8 \mathrm{H}, \mathrm{m}\right.$, succ.- $\left.\mathrm{CH}_{2}\right), 2.970(8 \mathrm{H}, \mathrm{m}$, exterior DOPA-CH 2$), 3.142-3.170$ $\left(4 \mathrm{H}, \mathrm{m}\right.$, core DOPA- $\left.\mathrm{CH}_{2}\right), 4.138\left(4 \mathrm{H}, \mathrm{m}\right.$, core $\left.\mathrm{OCH}_{2} \mathrm{CH}_{2} \mathrm{O}\right), 4.240(8 \mathrm{H}, \mathrm{m}$, exterior $\left.\mathrm{OCH}_{2} \mathrm{CH}_{2} \mathrm{O}\right), 4.310\left(8 \mathrm{H}, \mathrm{m}\right.$, exterior $\left.\mathrm{OCH}_{2} \mathrm{CH}_{2} \mathrm{O}\right), 4.359$ (6H, m, DOPA-CH), 6.473 (4H,d-d, $J=4.6$ and $1.1 \mathrm{~Hz}$, exterior 6-ArH), $6.609(4 \mathrm{H}, \mathrm{t}, J=1.2 \mathrm{~Hz}$, exterior 2-ArH), $6.660\left(4 \mathrm{H}, \mathrm{d}, J=4.8 \mathrm{~Hz}\right.$, exterior 5-ArH), 7.085-7.130 (6H, m, core-ArH) ${ }^{13} \mathrm{C}$ NMR $\left(\mathrm{CD}_{3} \mathrm{OD}\right) \delta^{13 \mathrm{C}}(75 \mathrm{MHz}): 29.583,29.663$, and $29.709\left(\right.$ succ.- $\left.-\mathrm{CH}_{2}\right), 36.440$ and 36.707 
(DOPA- $\mathrm{CH}_{2}$ ), 55.007 and 55.324 (DOPA -CH), 63.225, 63.356 and $65.248\left(\mathrm{OCH}_{2} \mathrm{CH}_{2} \mathrm{O}\right)$, $116.859,117.454,121.947,125.258,125.776,126.268,129.201,134.739$ (Ar-CH), 143.191, 143.737, 146.158, 146.780 (Ar-C), 169.718, 170.091, 172.124, 172.269 (DOPA-CO), 173.806, 173.825 (succ.-CO); MALDI-TOF-MS found [M+Na] ${ }^{+} 1735.7$ and $[\mathrm{M}+\mathrm{K}]^{+} 1751.7 ; \mathrm{C}_{80} \mathrm{H}_{92} \mathrm{~N}_{6} \mathrm{O}_{36}$ requires 1713.6.

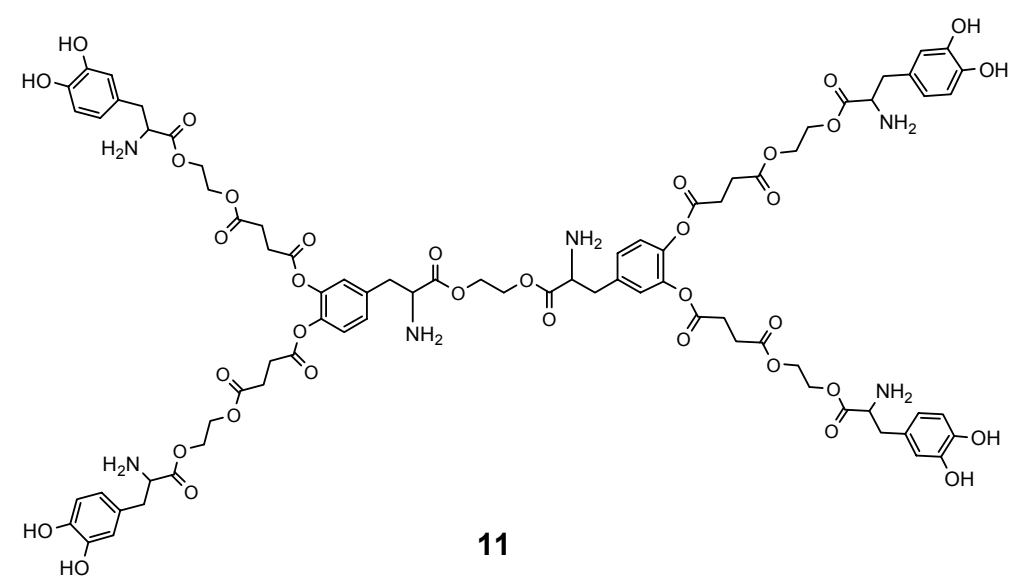

BnO-G2-NHBoc 12: To HO-G1-NHBoc 10 (175 mg, $0.075 \mathrm{mmol})$ in $\mathrm{CH}_{2} \mathrm{Cl}_{2}(10 \mathrm{~mL})$ were added building block 6 (451 $\mathrm{mg}, 0.72 \mathrm{mmol})$ and DPTS (43 mg, $0.22 \mathrm{mmol})$. The mixture was cooled at $0^{\circ} \mathrm{C}$ and $\mathrm{DCC}\left(1 \mathrm{M}\right.$ in $\left.\mathrm{CH}_{2} \mathrm{Cl}_{2}\right)(0.76 \mathrm{~mL}, 0.76 \mathrm{mmol})$ was added dropwise. The reaction mixture was allowed to warm to room temperature and stirred 36 h. The reaction was quenched with water $(10 \mathrm{~mL})$. The solid (DCU) was filtered off and washed with cool $\mathrm{CH}_{2} \mathrm{Cl}_{2}(2 \mathrm{~mL})$. The organic layer was separated and washed with water $(10 \mathrm{~mL})$, brine $(10 \mathrm{~mL})$, dried over $\mathrm{MgSO}_{4}$, filtered and then concentrated. The sediment was dissolved in 1:1 EtOAc/hexanes $(10 \mathrm{~mL})$ to precipitate extra DCU. The solution was filtered and concentrated. A flash chromatography (5:3 EtOAc /hexane) afforded BnO-G2-NHBoc 12 as a colorless solid (385 mg, 72\%). ${ }^{1} \mathrm{H}$ NMR $\left(\mathrm{CDCl}_{3}\right) \delta^{1} \mathrm{H}$ (300 MHz): 1.414, 1.434, and 1.437 (126H, b, Boc- $\left.\mathrm{CH}_{3}\right), 2.702$ (24H, m, succ. $\left.-\mathrm{CH}_{2}\right)$, $2.852\left(24 \mathrm{H}, \mathrm{m}\right.$, succ. $\left.-\mathrm{CH}_{2}\right), 2.986\left(28 \mathrm{H}, \mathrm{b}, \mathrm{DOPA}-\mathrm{CH}_{2}\right), 4.227\left(52 \mathrm{H}, \mathrm{b}, \mathrm{OCH}_{2} \mathrm{CH}_{2} \mathrm{O}\right)$, 
4.515 (14H, b, DOPA-CH), 4.880 (14H, b, DOPA-NH), 5.130 (32H, b, Benzyl-CH ${ }_{2}$, $6.444(8 \mathrm{H}, \mathrm{d}-\mathrm{d}, J=5.1$ and $1.2 \mathrm{~Hz}$, exterior 6-ArH), 6.747 (8H, s, exterior 2-ArH), 6.850 $(8 \mathrm{H}, \mathrm{d}, J=5.1 \mathrm{~Hz}$, exterior 5-ArH), $7.016(12 \mathrm{H}, \mathrm{m}$, interior-ArH $), 7.061(6 \mathrm{H}, \mathrm{m}$, core$\mathrm{ArH}) ;{ }^{13} \mathrm{C} \mathrm{NMR}\left(\mathrm{CDCl}_{3}\right) \delta^{13} \mathrm{C}(75 \mathrm{MHz}): 28.235$ and $28.288\left(\right.$ Boc- $\left.\mathrm{CH}_{3}\right), 28.601$ (succ.$\mathrm{CH}_{2}$ ), 37.307 and 37.547 (DOPA- $\mathrm{CH}_{2}$ ), 54.323 (DOPA-CH), 62.251, 62.762, and 63.021 $\left(\mathrm{OCH}_{2} \mathrm{CH}_{2} \mathrm{O}\right), 71.254$ and $71.369\left(40 \mathrm{H}\right.$, Benzyl- $\left.\mathrm{CH}_{2}\right), 79.922$ and 80.022 (Boc-C), 115.083, 116.326, 122.324, 123.323, 124.178, and 129.145( Ar-CH), 127.261 and 127.329 (2-C, 2'-C, Benzyl), 127.749 and 127.795 (3-C, 3'-C, Benzyl), 128.428 and128.459 (4-C, 4'-C , Benzyl), 137.172 and 137.264 (1-, 1'-C, Benzyl), 135.082, 140.980, 141.850, 148.160, 148.893 ( Ar-C), 155.058 (Boc-CO), 169.769, 169.861 (DOPA-CO), 171.387, 171.715,171.860 (succ.-CO).

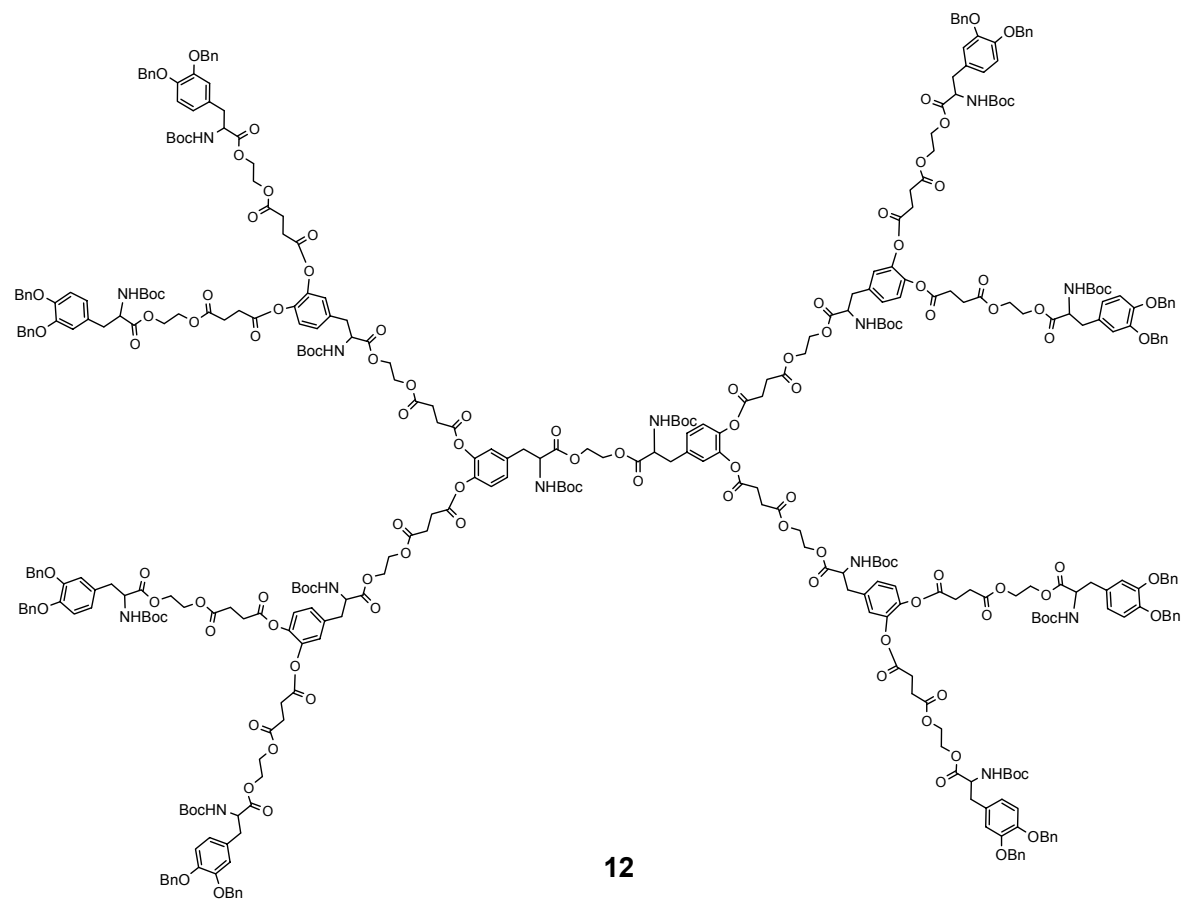

HO-G2-NHBoc 13: To a solution of BnO-G2-NHBoc 12 (312 mg, $0.043 \mathrm{mmol})$ in THF $(6 \mathrm{~mL})$ in a Parr tube was added 5\% palladium on charcoal $(100 \mathrm{mg})$. The Parr tube was evacuated, and filled with $50 \mathrm{psi}$ of $\mathrm{H}_{2}$. The solution was shaken for $6 \mathrm{~h}$. The catalyst was 
filtered off and washed with THF ( $2 \mathrm{~mL})$. The filtrate was concentrated. A flash chromatography (5\% methanol in ethyl acetate) afforded HO-G2-NHBoc $\mathbf{1 3}$ as a white solid (224 mg, 90\%). ${ }^{1} \mathrm{H}$ NMR ( $\left.\mathrm{CDCl}_{3}\right) \delta^{\prime} \mathrm{H}(300 \mathrm{MHz}): 1.375$, and $1.412(126 \mathrm{H}, \mathrm{b}$, Boc$\left.\mathrm{CH}_{3}\right), 2.696\left(24 \mathrm{H}\right.$, b, succ.- $\left.\mathrm{CH}_{2}\right), 2.882\left(24 \mathrm{H}, \mathrm{b}\right.$, succ. $\left.-\mathrm{CH}_{2}\right), 3.009\left(28 \mathrm{H}, \mathrm{b}, \mathrm{DOPA}-\mathrm{CH}_{2}\right)$, 4.221 and $4.303\left(52 \mathrm{H}, \mathrm{b}, \mathrm{OCH}_{2} \mathrm{CH}_{2} \mathrm{O}\right), 4.497(14 \mathrm{H}, \mathrm{b}, \mathrm{DOPA}-\mathrm{CH}), 5.144$ and 5.324 (14H, b, DOPA-NH), 6.485 (8H, d, $J=7.8 \mathrm{~Hz}$, exterior 6-ArH), 6.587 (8H, d, $J=6.0$, exterior 2-ArH), 6.705 (8H, d, $J=6.6 \mathrm{~Hz}$, exterior 5-ArH), 6.948-6.986 (12H, b, interiorArH), 7.023-7.049(6H, m, core-ArH); ${ }^{13} \mathrm{C}$ NMR $\left(\mathrm{CDCl}_{3}\right) \delta^{13} \mathrm{C}(75 \mathrm{MHz}): 28.189$ and

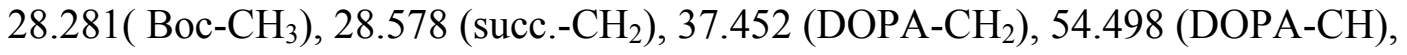
62.403, 62.846, and $63.182\left(\mathrm{OCH}_{2} \mathrm{CH}_{2} \mathrm{O}\right), 80.251$ (Boc-C), 115.304, 116.067, 121,301, 123.362, 124.224, 127.741 (Ar-CH), 135.265, 140.835, 141.728, 143.330, 144.116 (ArC), 155.439 (Boc-CO), 170.616, 170. 686 (DOPA-CO), 171.989172 .249 (succ.-CO);

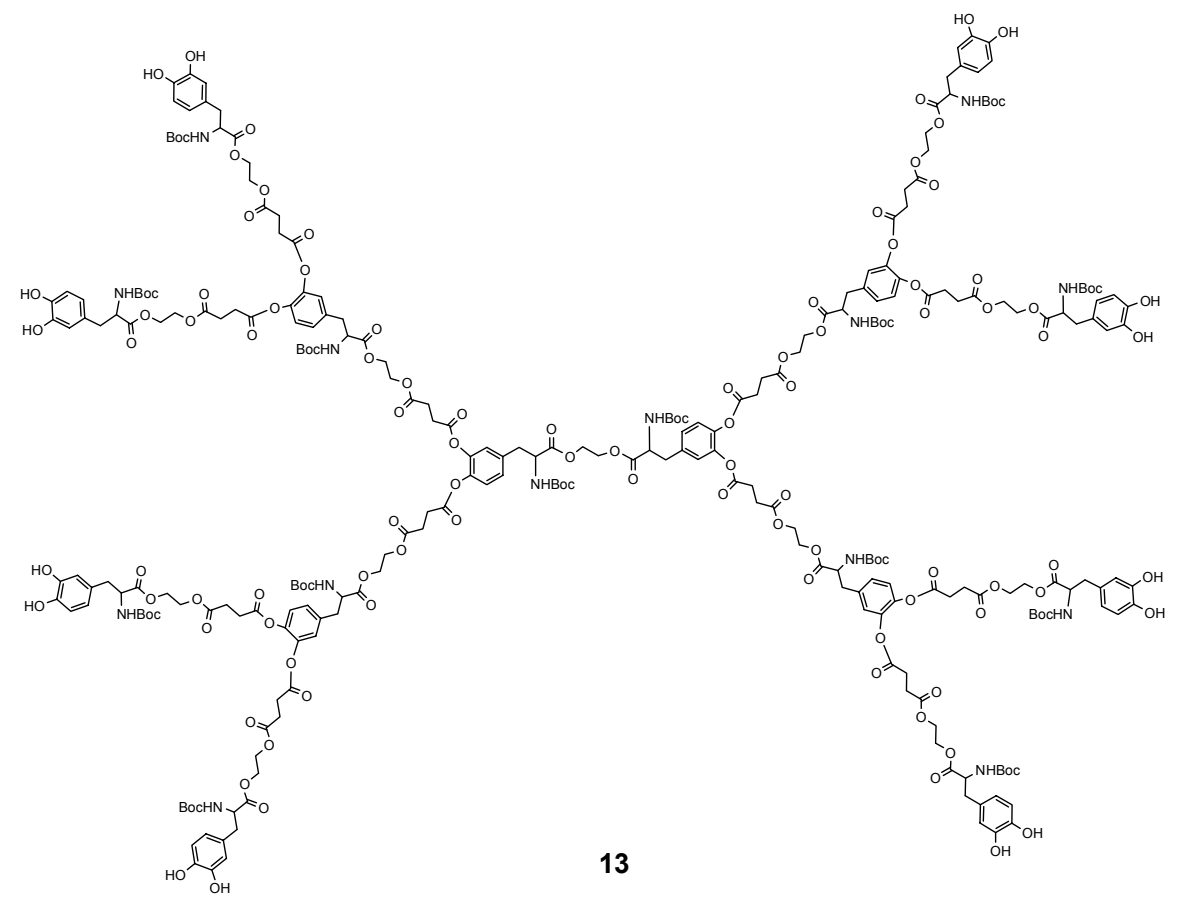

HO-G2-NH 2 14: To HO-G2-NHBoc $13(132 \mathrm{mg}, 0.023 \mathrm{mmol})$ a solution of $4 \mathrm{M} \mathrm{HCl}$ in dioxane $(2 \mathrm{~mL})$ was added. The reaction mixture was stirred at room temperature for 5 
minutes. The chlorate of $\mathbf{1 1}$ was precipitated. The solvent and the remaining $\mathrm{HCl}$ were removed and the sediment was washed with DCM $(2 \times 2 \mathrm{~mL})$. Drying gave the product HO-G2-NH $\mathrm{NH}_{2} 14$ as a white powder $(95 \mathrm{mg}, 86 \%) .{ }^{1} \mathrm{H} \mathrm{NMR}\left(\mathrm{CD}_{3} \mathrm{OD}\right) \delta^{\prime} \mathrm{H}(300 \mathrm{MHz})$ : $2.622\left(24 \mathrm{H}, \mathrm{b}\right.$, succ.- $\left.\mathrm{CH}_{2}\right), 2.817$ (24H, b, succ.- $\left.\mathrm{CH}_{2}\right), 2.937$ (16H, b, exterior DOPA$\left.\mathrm{CH}_{2}\right), 3.176-3.198\left(12 \mathrm{H}, \mathrm{b}\right.$, interior and core DOPA- $\left.\mathrm{CH}_{2}\right), 4.115(4 \mathrm{H}, \mathrm{m}$, core $\left.\mathrm{OCH}_{2} \mathrm{CH}_{2} \mathrm{O}\right), 4.220-4.232\left(24 \mathrm{H}, \mathrm{m}\right.$, exterior $\left.\mathrm{OCH}_{2} \mathrm{CH}_{2} \mathrm{O}\right), 4.298(24, \mathrm{~m}, 24 \mathrm{H}$, exterior $\left.\mathrm{OCH}_{2} \mathrm{CH}_{2} \mathrm{O}\right), 4.336(14, \mathrm{~m}, \mathrm{DOPA}-\mathrm{CH}), 6.442(8 \mathrm{H}, \mathrm{d}-\mathrm{d}, J=7.8$ and $1.8 \mathrm{~Hz}$, exterior 6ArH), $6.570(8 \mathrm{H}, \mathrm{s}$, exterior 2-ArH), $6.630(8 \mathrm{H}, \mathrm{d}, J=8.1 \mathrm{~Hz}$, exterior 5-ArH), 7.047 (6H, b, core- $\mathrm{ArH}), 7.081(12 \mathrm{H}, \mathrm{b}$, interior-ArH $) ;{ }^{13} \mathrm{C} \mathrm{NMR}\left(\mathrm{CD}_{3} \mathrm{OD}\right) \delta^{13 \mathrm{C}}(75 \mathrm{MHz})$ : 29.642 (succ.- $\mathrm{CH}_{2}$ ), 36.753 (DOPA-CH 2 ), 55.295 (DOPA-CH), 63.353, 65.260, and $68.129\left(\mathrm{OCH}_{2} \mathrm{CH}_{2} \mathrm{O}\right), 116.833,117.413,121.922,125.333,125.844,126.249,129.232$ and 134.634 (Ar-CH), 143.280, 143.791, 146.210, 146.843 (Ar-C), 169.818, 170.176, 172.160, 172.336 (DOPA-CO), 173.839 (succ.-CO); MALDI-TOF-MS found [M+Na] 4324.2; $\mathrm{C}_{200} \mathrm{H}_{228} \mathrm{~N}_{14} \mathrm{O}_{92}$ requires 4300.2

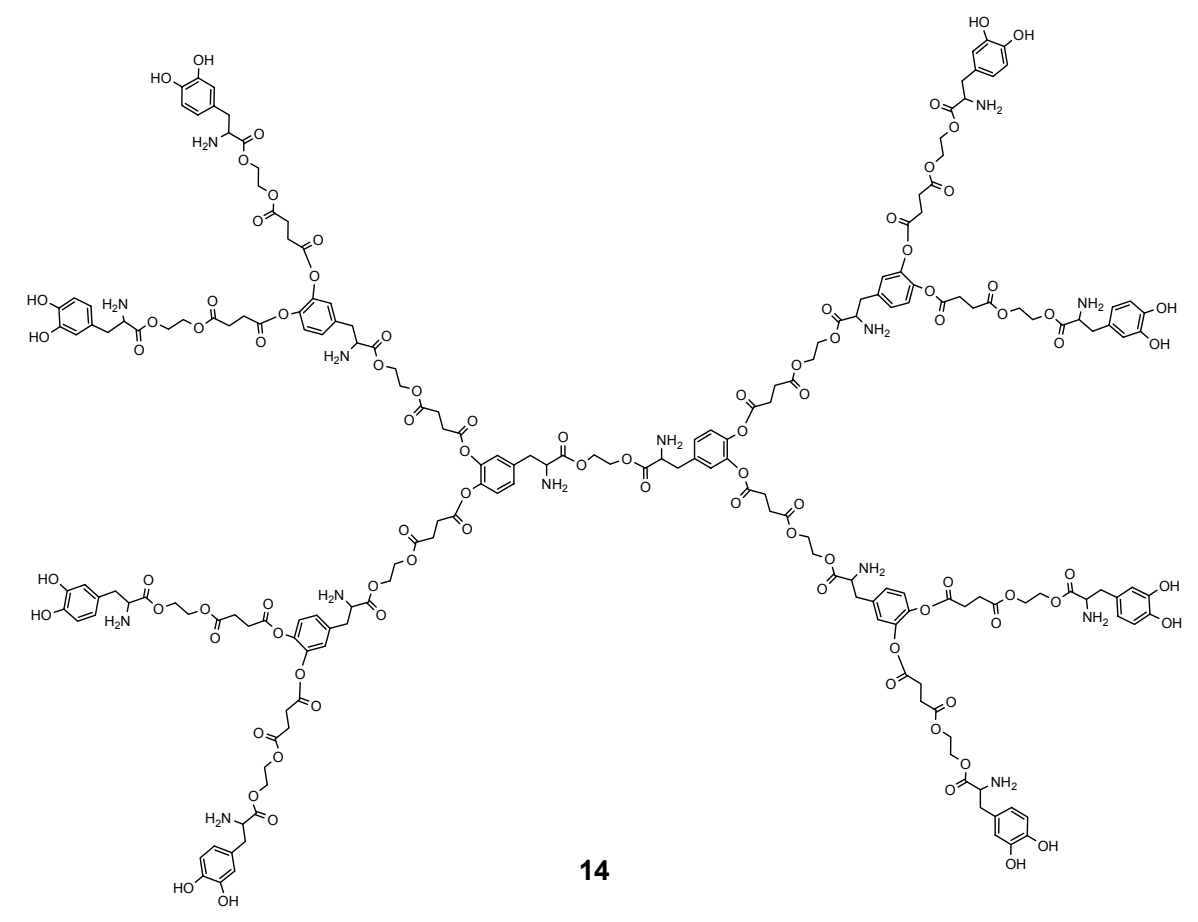


BnO-G3-NHBoc 15: To HO-G2-NHBoc 13 (81 mg, $0.014 \mathrm{mmol})$ in $\mathrm{CH}_{2} \mathrm{Cl}_{2}(10 \mathrm{~mL})$ were added building block 6 (169 mg, $0.27 \mathrm{mmol})$ and DPTS (20 mg, $0.08 \mathrm{mmol})$. The mixture was cooled at $0^{\circ} \mathrm{C}$ and $\mathrm{DCC}\left(1 \mathrm{M}\right.$ in $\left.\mathrm{CH}_{2} \mathrm{Cl}_{2}\right)(0.3 \mathrm{~mL}, 0.3 \mathrm{mmol})$ was added dropwise. The reaction mixture was allowed to warm to room temperature and stirred 72 h. The DCU was filtered off and washed with cool $\mathrm{CH}_{2} \mathrm{Cl}_{2}(2 \mathrm{~mL})$. The filtrate was concentrated to dryness and the residue was resuspended in 1:1 EtOAc/hexanes $(10 \mathrm{~mL})$. The solution was filtered and concentrated. A flash chromatography (1:1 to 2:1 EtOAc /hexane) afforded BnO-G3-NHBoc 15 as a colorless solid (146 mg, 68\%). ${ }^{1} \mathrm{H}$ NMR $\left(\mathrm{CDCl}_{3}\right) \delta^{\prime} \mathrm{H}(300 \mathrm{MHz}): 1.388\left(270 \mathrm{H}, \mathrm{b}, \mathrm{Boc}-\mathrm{CH}_{3}\right), 2.689\left(56 \mathrm{H}, \mathrm{b}\right.$, succ. $\left.-\mathrm{CH}_{2}\right), 2.847$ $\left(56 \mathrm{H}, \mathrm{b}\right.$, succ. $\left.-\mathrm{CH}_{2}\right), 2.966\left(60 \mathrm{H}, \mathrm{b}, \mathrm{DOPA}-\mathrm{CH}_{2}\right), 4.218$ and $4.268(116 \mathrm{H}, \mathrm{b}$, $\left.\mathrm{OCH}_{2} \mathrm{CH}_{2} \mathrm{O}\right), 4.518$ (30H, b, DOPA-CH), 4.979(30H, b, DOPA-NH), 5.093 (64H, b, Benzyl $\left.-\mathrm{CH}_{2}\right), 6.636(16 \mathrm{H}, \mathrm{d}, J=7.5 \mathrm{~Hz}$, exterior 6-ArH), $6.741(16 \mathrm{H}$, s, exterior 2-ArH), $6.840(16 \mathrm{H}, \mathrm{d}, J=8.4 \mathrm{~Hz}$, exterior 5-ArH), 6.967-7.071 (42H, b, interior-ArH), 7.3087.405 (160H, b, Benzyl-ArH); ${ }^{13} \mathrm{C}$ NMR $\left(\mathrm{CDCl}_{3}\right) \delta^{13} \mathrm{C}(75 \mathrm{MHz}): 28.227$ and 28.281 (Boc- $\mathrm{CH}_{3}$ ), 28.593 (succ.- $\mathrm{CH}_{2}$ ), 37.261 and 37.559 (DOPA-CH $), 54.315$ (DOPA-CH), 62.243, 62.754, and 63.006 $\left(\mathrm{OCH}_{2} \mathrm{CH}_{2} \mathrm{O}\right), 71.239$ and $71.361\left(\mathrm{Benzyl}-\mathrm{CH}_{2}\right), 79.900$ and 79.999 (Boc-C), 115.068, 116.311, 122.316, 123.323, 124.178, and 129.145(Ar-CH), 127.245 and 127.322 (2-C, 2'-C, Benzyl), 127.741 and 127.787 (3-C, 3'-C, Benzyl), 128.421 and128.443 (4-C, 4'-C , Benzyl), 137.165 and 137.256 (1-, 1'-C, Benzyl), 135.097, 140.972, 141.842, 148.152, 148.885 (Ar-C), 155.050 (Boc-CO), 169.754, 169.845 (DOPA-CO), 171.402, 171.707,171.844 (succ.-CO). 


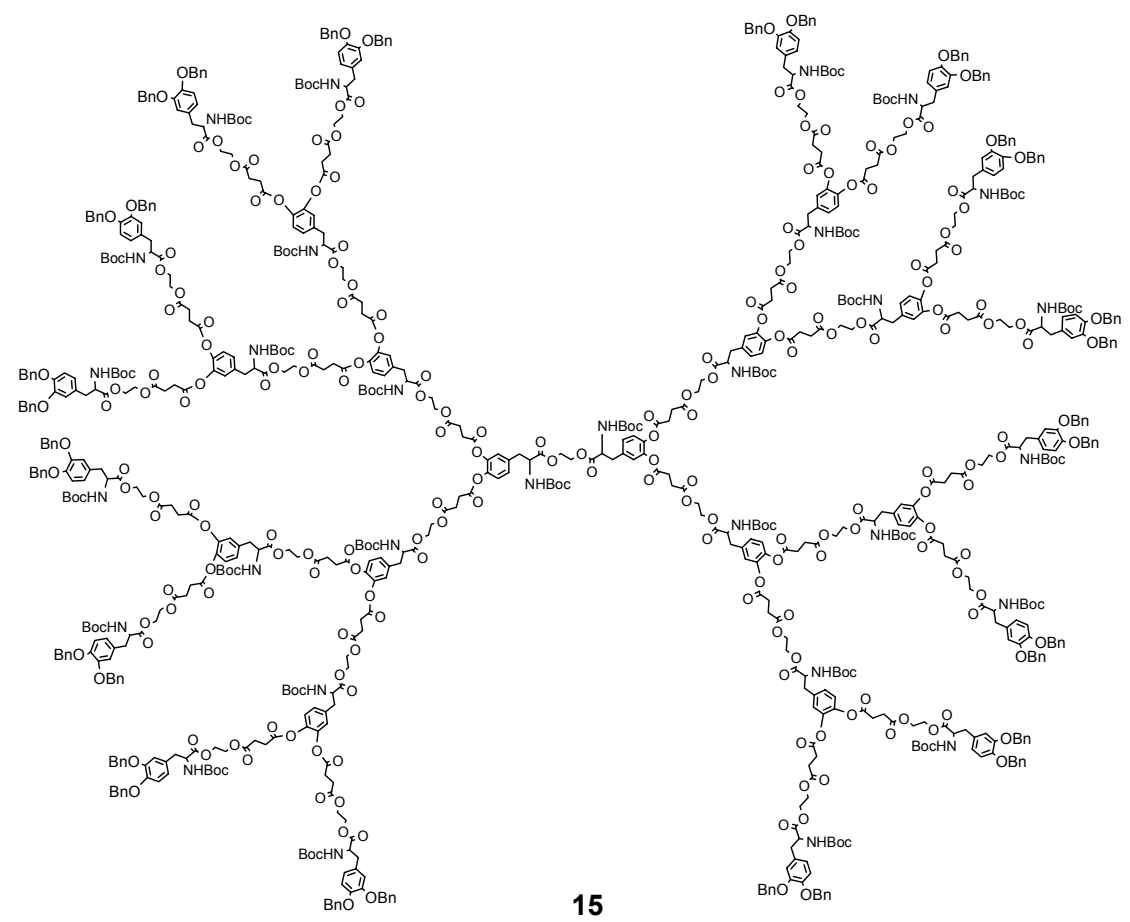

HO-G3-NHBoc 16: To BnO-G3-NHBoc 15 (136 mg, $0.0088 \mathrm{mmol})$ in THF (10 mL) in a Parr tube was added 5\% palladium on charcoal $(100 \mathrm{mg})$, and the flask was evacuated and filled with 50 psi of $\mathrm{H}_{2}$. The mixture was shaken for $6 \mathrm{~h}$, and then filtered. The filtrate was dried. A flash chromatography (10\% methanol in ethyl acetate) afforded HO-G3NHBoc 16 as a colorless solid (99 mg, 90\%). ${ }^{1} \mathrm{H}$ NMR $\left(\mathrm{CDCl}_{3}\right) \delta^{1} \mathrm{H}(300 \mathrm{MHz}): 1.379$, and $1.407\left(270 \mathrm{H}, \mathrm{b}\right.$, Boc- $\left.-\mathrm{CH}_{3}\right), 2.691\left(56 \mathrm{H}, \mathrm{b}\right.$, succ. $\left.-\mathrm{CH}_{2}\right), 2.867\left(56 \mathrm{H}, \mathrm{b}\right.$, succ. $\left.-\mathrm{CH}_{2}\right)$, 2.929-3.010 (60H, b, DOPA-CH 2$), 4.233$ and $4.305\left(116 \mathrm{H}, \mathrm{b}, \mathrm{OCH}_{2} \mathrm{CH}_{2} \mathrm{O}\right), 4.481$ and $4.929(30 \mathrm{H}, \mathrm{b}, \mathrm{DOPA}-\mathrm{CH}), 5.122$ and $5.314(30 \mathrm{H}, \mathrm{b}, \mathrm{DOPA}-\mathrm{NH}), 6.484(16 \mathrm{H}, \mathrm{d}, J=4.5$ Hz, exterior 6-ArH), $6.594(16 \mathrm{H}, \mathrm{d}, J=5.4 \mathrm{~Hz}$, exterior 2-ArH), 6.698 (16H, b, exterior 5-ArH), 6.952-7.048 (42H, b, interior-ArH); ${ }^{13} \mathrm{C} \mathrm{NMR}\left(\mathrm{CDCl}_{3}\right) \delta^{13} \mathrm{C}(75 \mathrm{MHz}): 28.281$ ( Boc- $\mathrm{CH}_{3}$ ), 28.624 (succ.- $\mathrm{CH}_{2}$ ), 37.467 (DOPA-CH$), ~ 54.246$ and 54.597 (DOPA-CH), 62.411, and 62.838 (-OCH$), 80.220$ (Boc-C), 115.342, 116.120, 121.249, 123.339, 
124.193, and 127.833( Ar-CH), 135.227, 140.888, 141.812, 143.361, 144.147 ( Ar-C), 155.424 (Boc-CO), 170.059, 170.502 (DOPA-CO), 172.203 (succ.-CO);

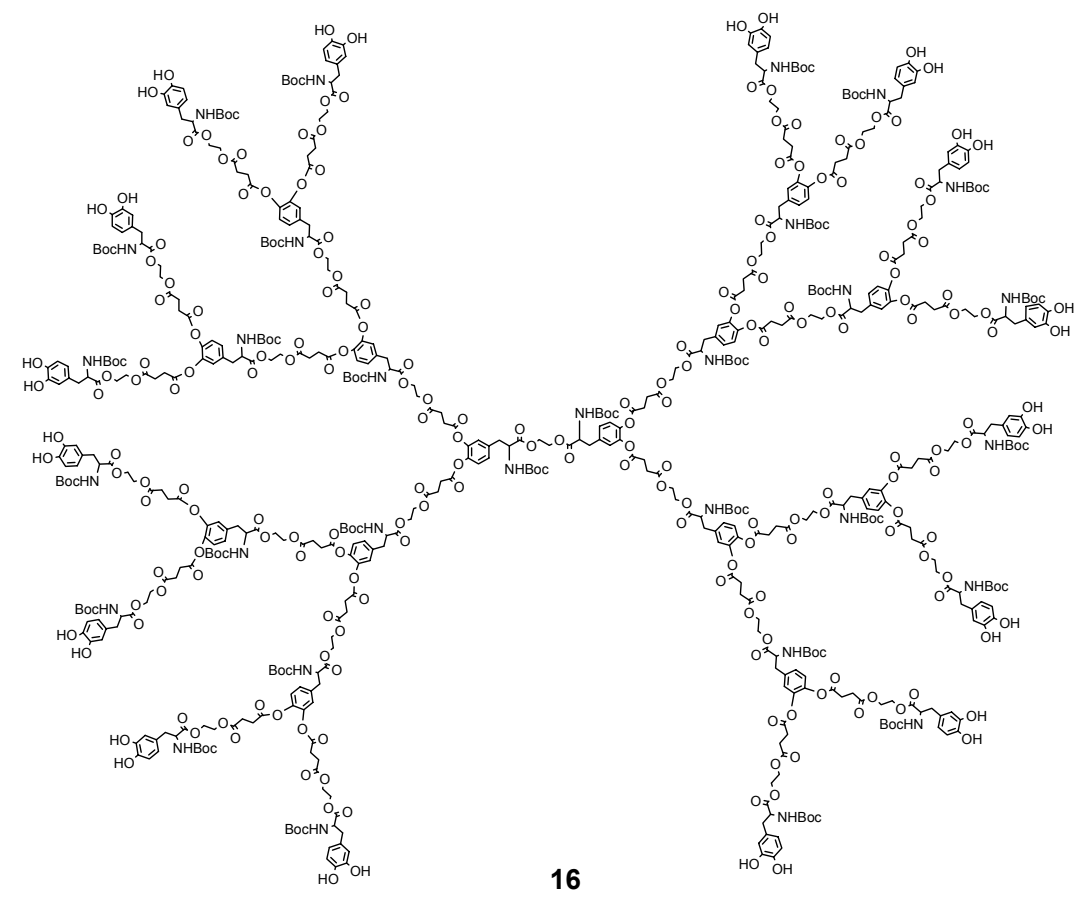

HO-G3-NH $\mathbf{N}_{2}$ 17: To HO-G3-NHBoc $16(88 \mathrm{mg}, 0.007 \mathrm{mmol})$ a solution of $4 \mathrm{M} \mathrm{HCl}$ in dioxane $(2 \mathrm{~mL})$ was added. The reaction mixture was stirred for 5 minutes. The chlorate of $\mathbf{1 6}$ was precipitated. The mixture was dried and the residue was washed with DCM $(2 \times 2 \mathrm{~mL})$. Drying afforded HO-G3- $\mathrm{NH}_{2} 17$ as a colorless powder $(61 \mathrm{mg}, 82 \%) .{ }^{1} \mathrm{H}$ NMR $\left(\mathrm{CD}_{3} \mathrm{OD}\right) \delta^{\prime}$ н $(300 \mathrm{MHz}): 2.608\left(56 \mathrm{H}, \mathrm{b}\right.$, succ.- $\left.\mathrm{CH}_{2}\right), 2.777-2.789(56 \mathrm{H}, \mathrm{b}$, succ.$\left.\mathrm{CH}_{2}\right), 2.858-2.953\left(32 \mathrm{H}, \mathrm{m}\right.$, exterior DOPA- $\left.\mathrm{CH}_{2}\right), 3.017-3.026(28 \mathrm{H}, \mathrm{b}$, interior and core DOPA- $\left.\mathrm{CH}_{2}\right), 4.167-4.219$ (116H, b, $\left.\mathrm{OCH}_{2} \mathrm{CH}_{2} \mathrm{O}\right), 4.305-4.381$ (30H, b, DOPA-CH), $6.468(16 \mathrm{H}, \mathrm{d}, J=4.8 \mathrm{~Hz}$, exterior 6-ArH), 6.569 (16H, s, exterior 2-ArH), $6.692(16 \mathrm{H}, \mathrm{d}$, $J=4.5 \mathrm{~Hz}$, exterior 5-ArH), 6.912 (6H, b, core- $\mathrm{ArH}), 7.007-7.069$ (36H, b, interior$\mathrm{ArH}) ;{ }^{13} \mathrm{C}$ NMR $\left(\mathrm{CD}_{3} \mathrm{OD}\right) \delta^{13} \mathrm{C}(75 \mathrm{MHz}): 28.669$ (succ.- $\left.\mathrm{CH}_{2}\right), 35.010$ (DOPA-CH ${ }_{2}$ ), 54.101 (DOPA-CH), 62.776, 64.501, $66.729\left(\mathrm{OCH}_{2} \mathrm{CH}_{2} \mathrm{O}\right), 116.570,116.997,121.827$, 126.069 (Ar-CH), 143.917, 144.519 (Ar-C), 169.119, 169.539, 172.553, (DOPA-CO), 
174.079 (succ.-CO); MALDI-TOF-MS found $[\mathrm{M}+\mathrm{H}]^{+}$9474.0; $\mathrm{C}_{440} \mathrm{H}_{500} \mathrm{~N}_{30} \mathrm{O}_{204}$ requires 9472.8 .

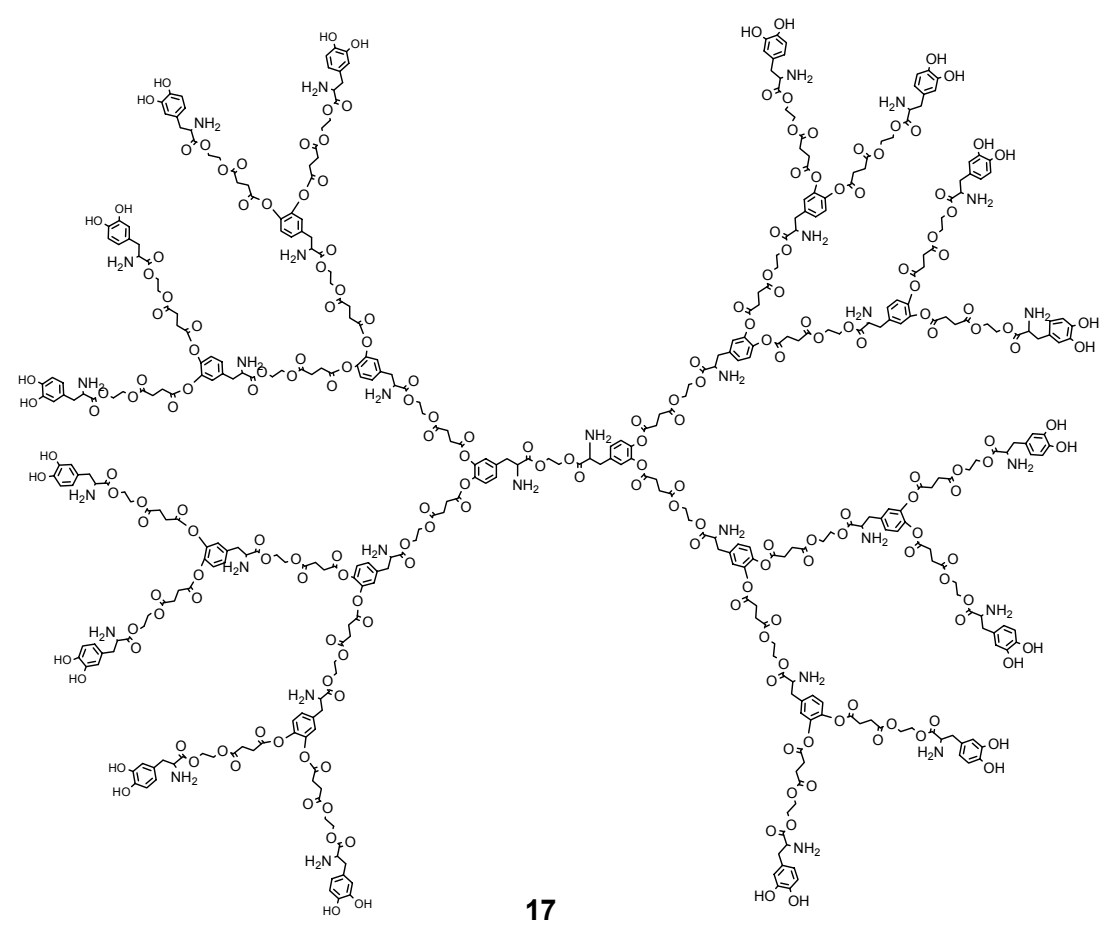

HO-G3-NH (The $^{\text {rd }}$ generation dendritic L-DOPA) 


\section{Gel electrophoresis Measurements}

The 5\% stacking gel was made in glacial acetic acid / $\mathrm{KOH}$ solution (final concentrations $0.75 \%$ and $120 \mathrm{mM}$, respectively, $\mathrm{pH}$ 5.9). Ammonium persulfate and TEMED concentration was $0.7 \%$ and $0.06 \%$, respectively. Resolving gel was made in glacial acetic acid / $\mathrm{KOH}$ solution (final concentrations $13.25 \%$ and $30 \mathrm{mM}$, respectively, $\mathrm{pH}$ 2.9). The concentrations of persulfate were similar to that of stacking gel. TEMED concentration was increased to $0.6 \%$. Under these conditions, polymerization took about 30-60 minutes. Electrode buffer was $0.16 \%$ acetic acid containing $0.6 \% \beta$-alanine. Loading buffer was $40 \%$ sucrose and $2 \%$ methylene blue. Samples were mixed with equal volumes of loading buffer for application onto the gel $(5 \mu \mathrm{L}$ sample plus $5 \mu \mathrm{L}$ loading buffer). Electrophoresis was performed in the cold $\left(4^{\circ} \mathrm{C}\right)$, at $200 \mathrm{~V}$, for $75 \mathrm{~min}$. After separation, the gel was placed in $0.25 \mathrm{M}$ bicarbonate buffer for about 5 minutes at room temperature. It was then transferred to a fresh solution of bicarbonate buffer (containing 0.5 $\mathrm{M}$ glutaraldehyde) and incubated at $4{ }^{\circ} \mathrm{C}$ for 1 hour. After fixation, the gel was rinsed with deionized water and placed in Coomassie Blue stain $(0.2 \%$ dye made in $50 \%$ methanol/ $10 \%$ acetic acid $)$ in the cold $\left(4^{\circ} \mathrm{C}\right)$ overnight. Destaining was carried out in $10 \%$ methanol/10\% acetic acid solution in the cold. 
3. NMR Spectra of Important Intermediates and Final Products

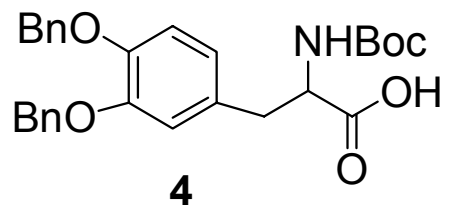

${ }^{1} \mathrm{H}$ NMR

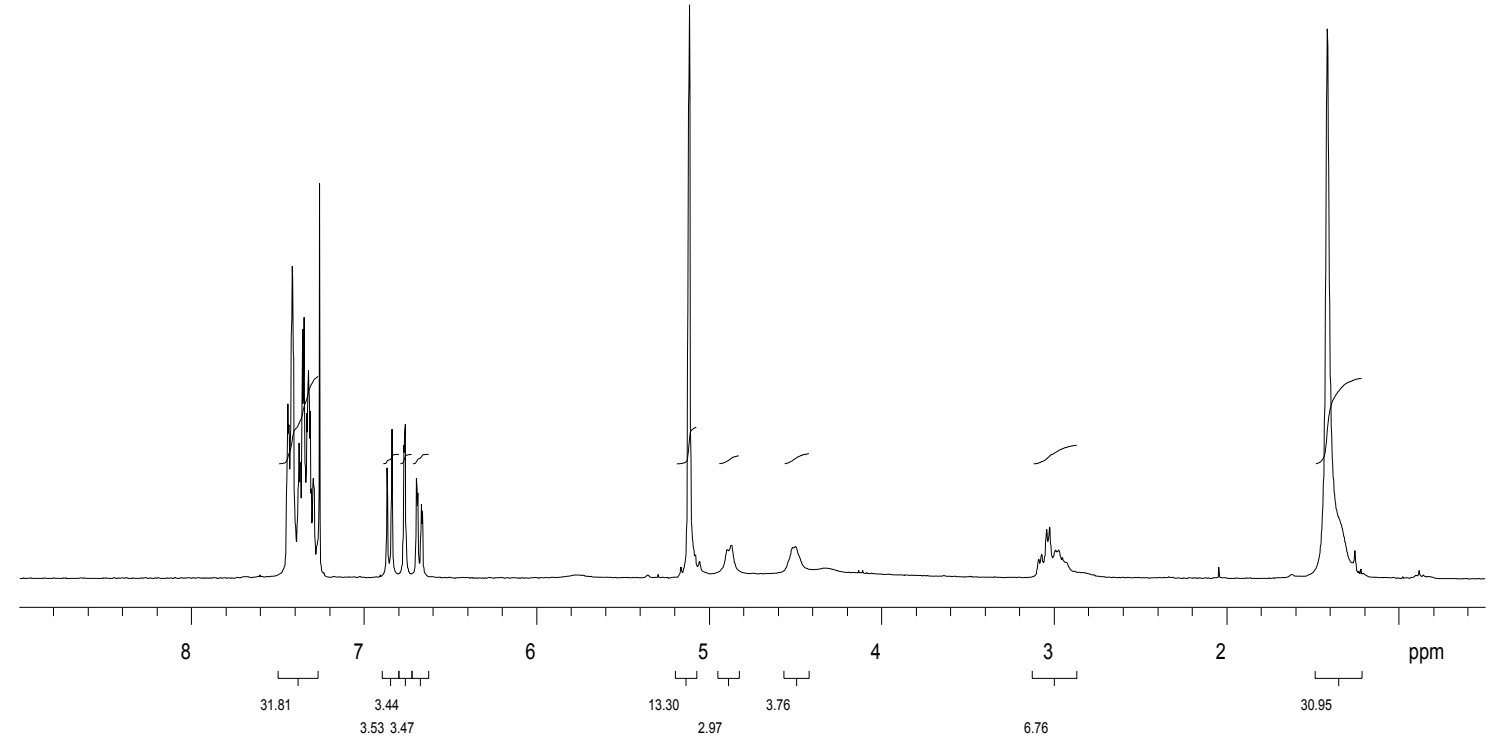

${ }^{13} \mathrm{C}$ NMR

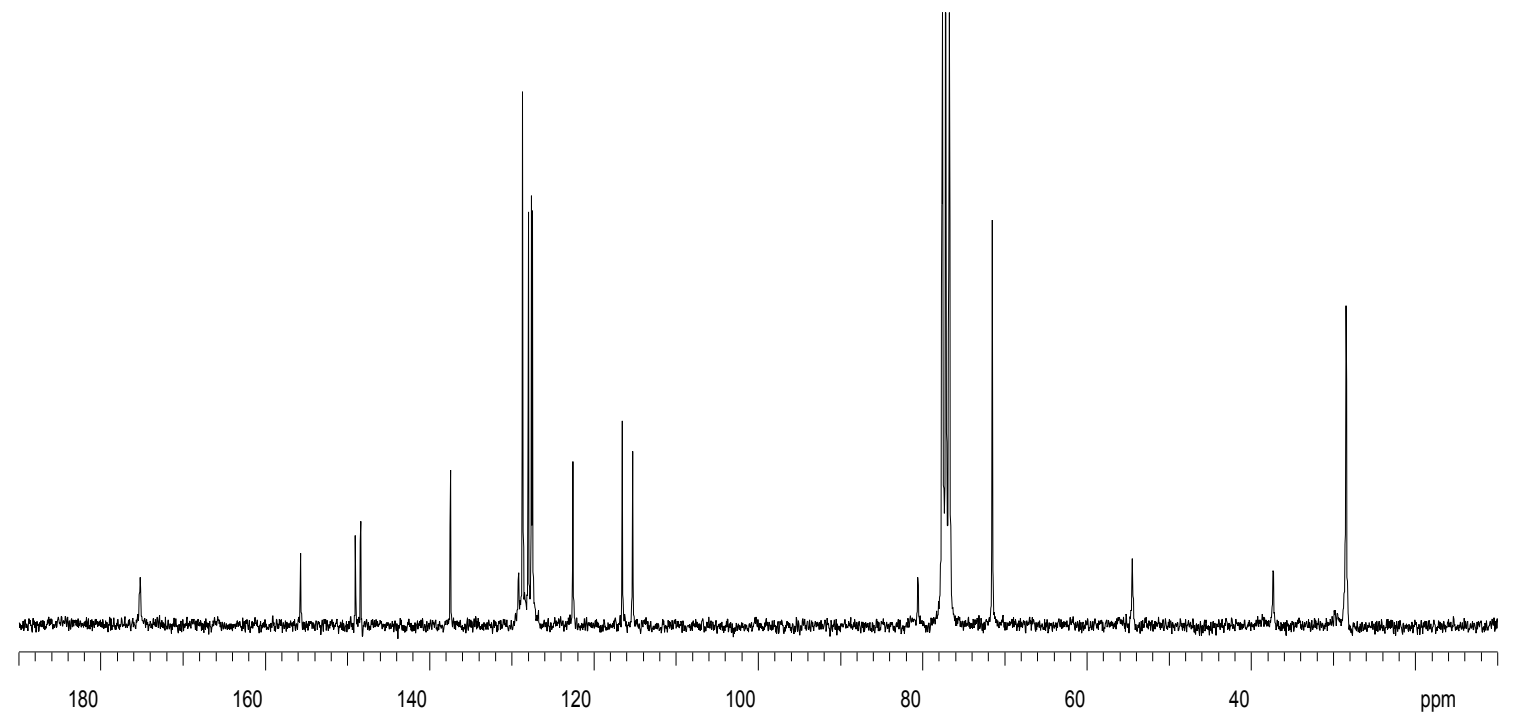




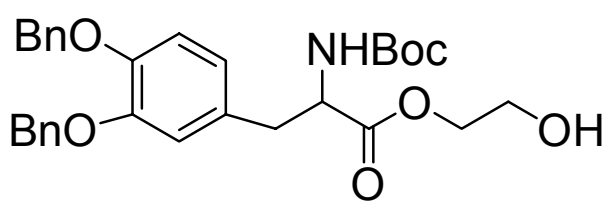

5

\section{${ }^{1} \mathrm{H}$ NMR}

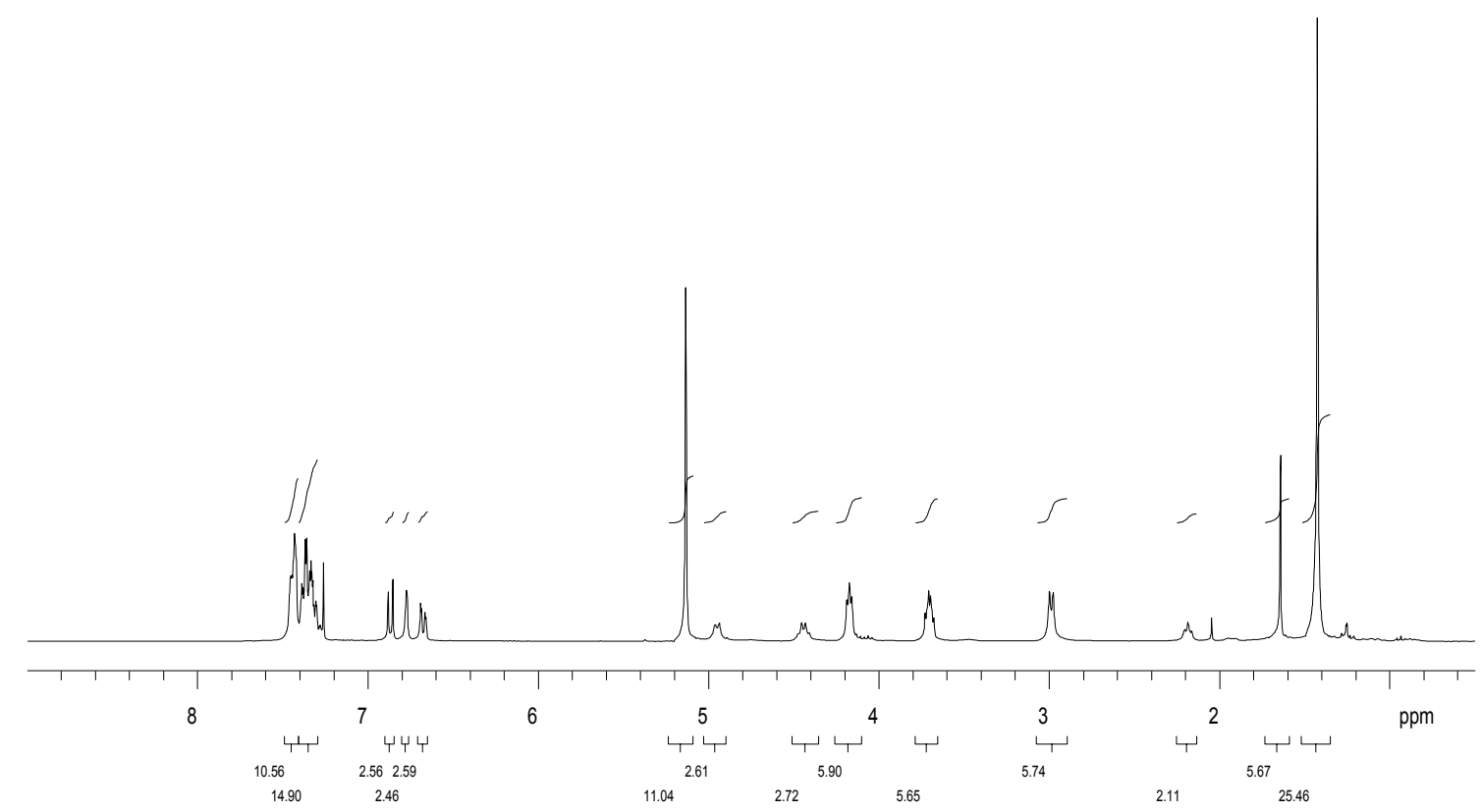

${ }^{13} \mathrm{C}$ NMR

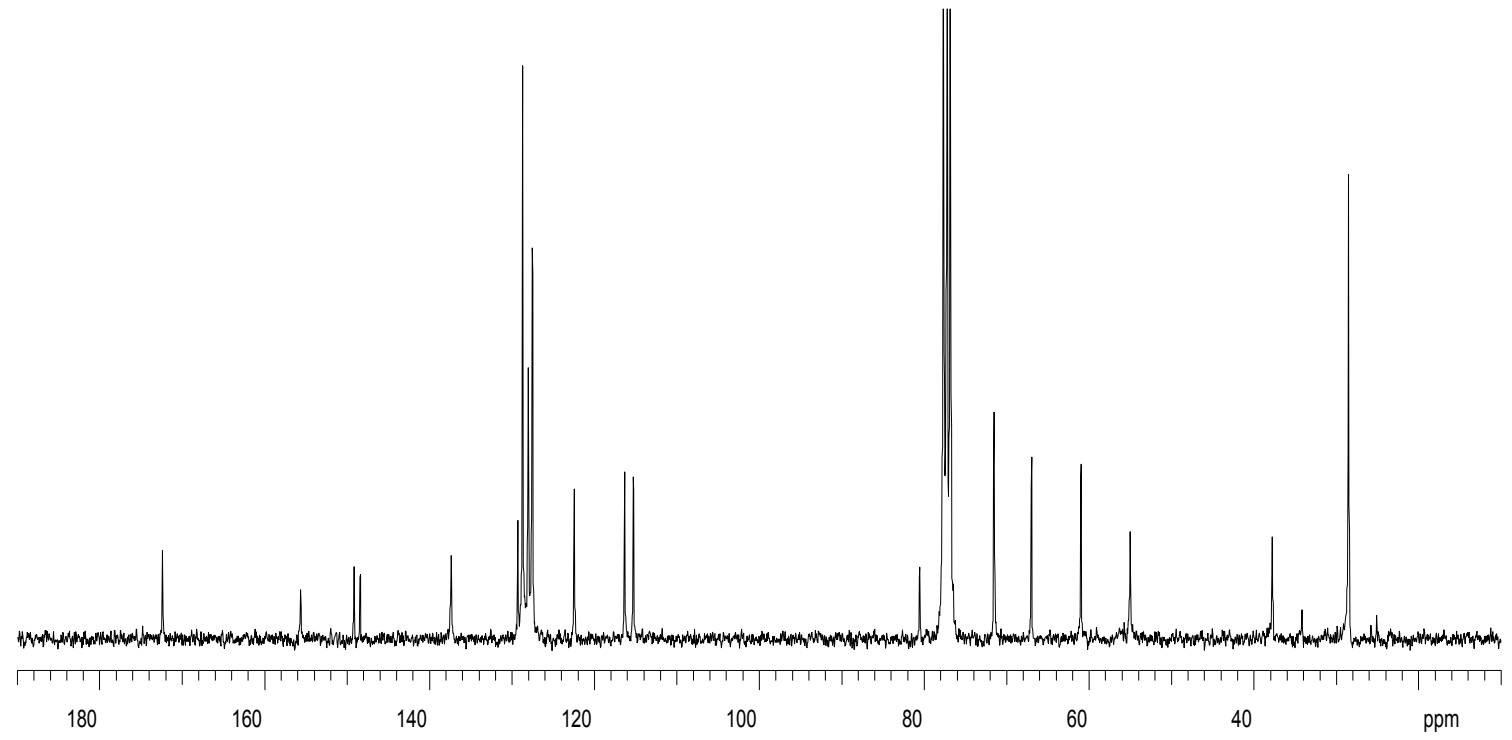



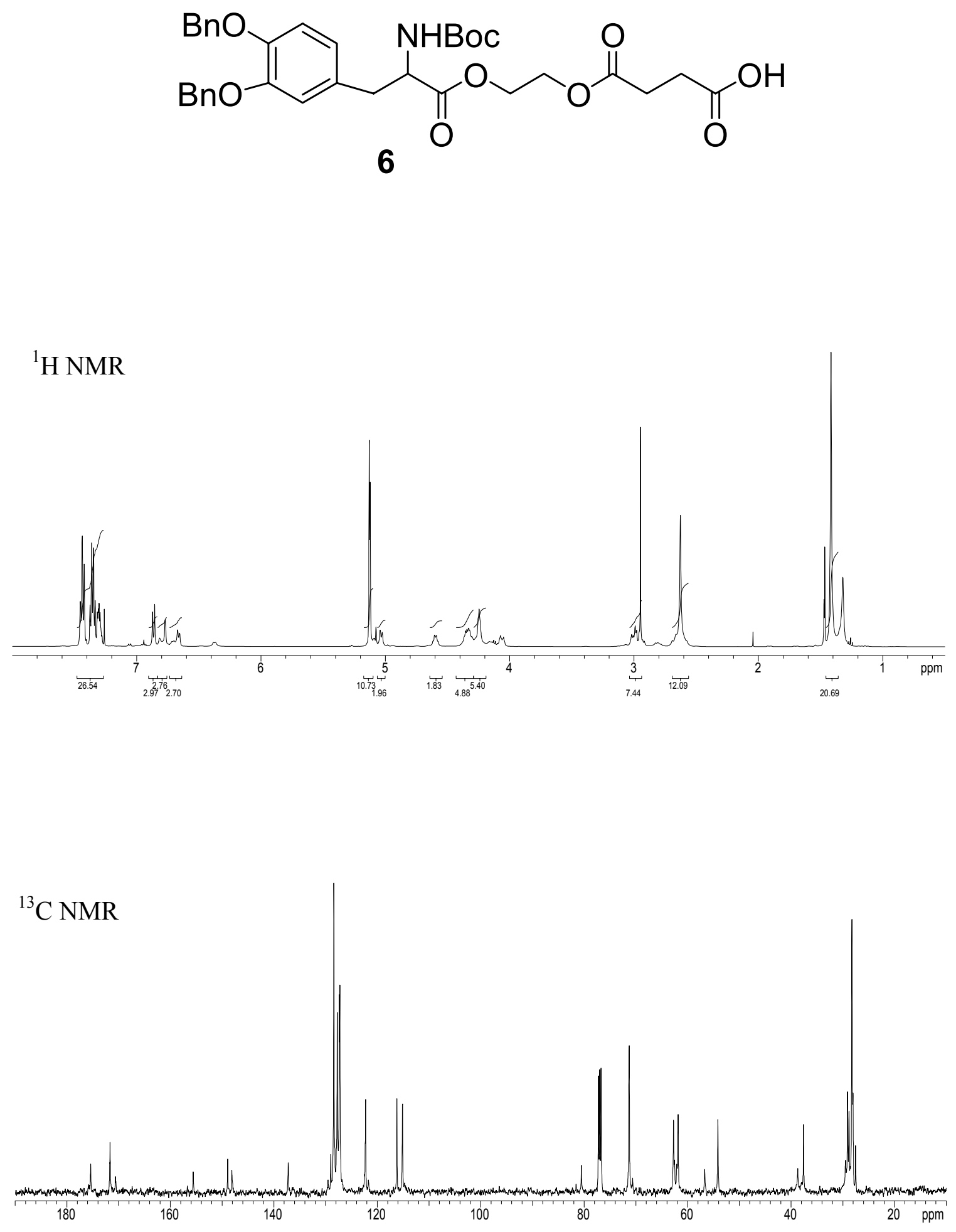


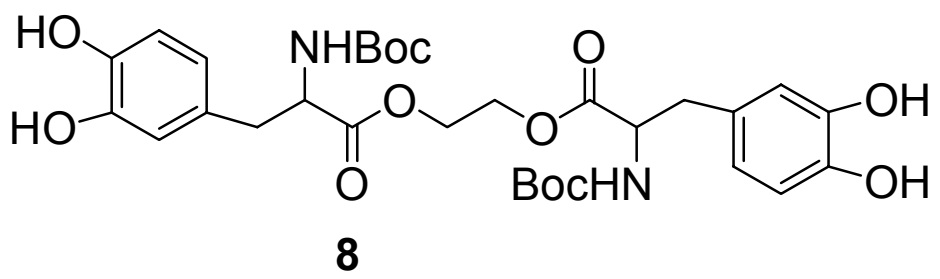

\section{${ }^{1} \mathrm{H}$ NMR}

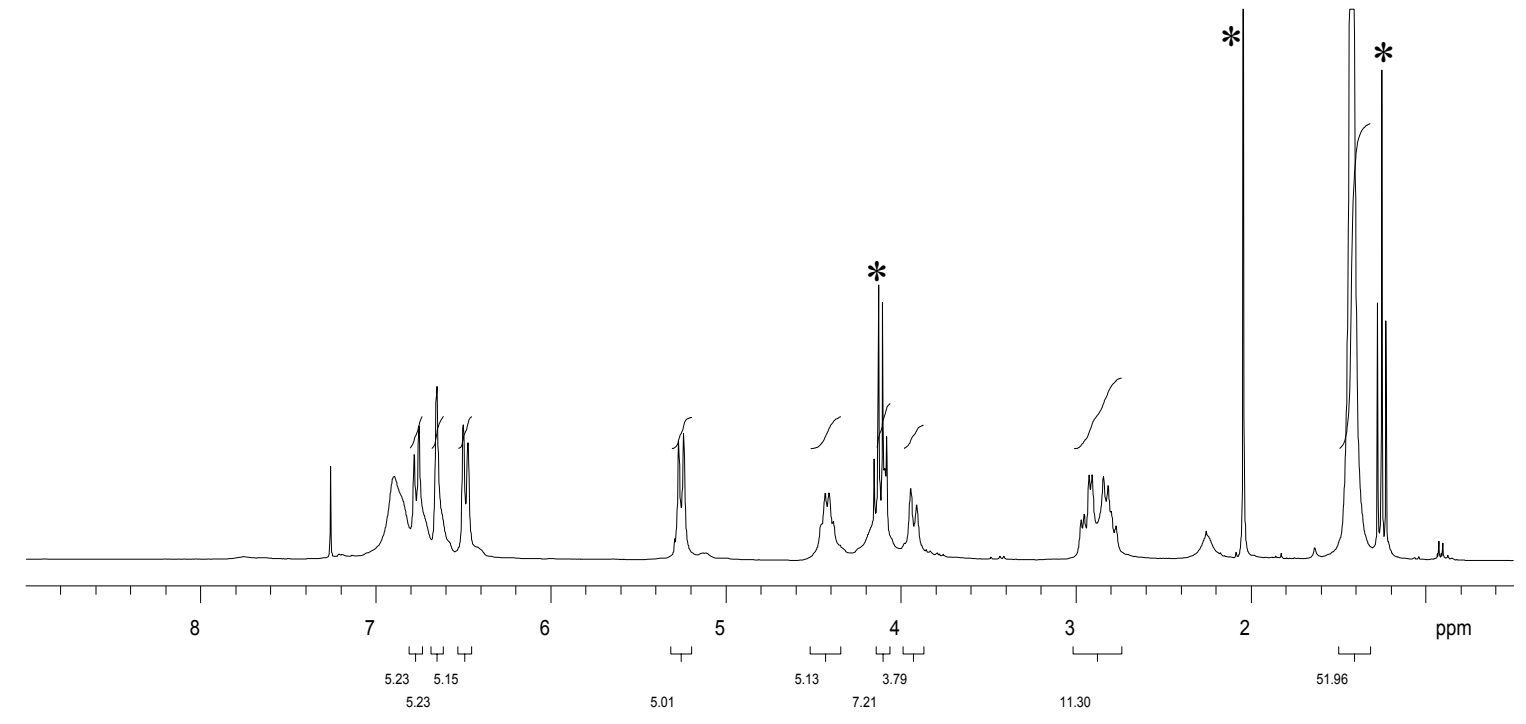

${ }^{13} \mathrm{C}$ NMR

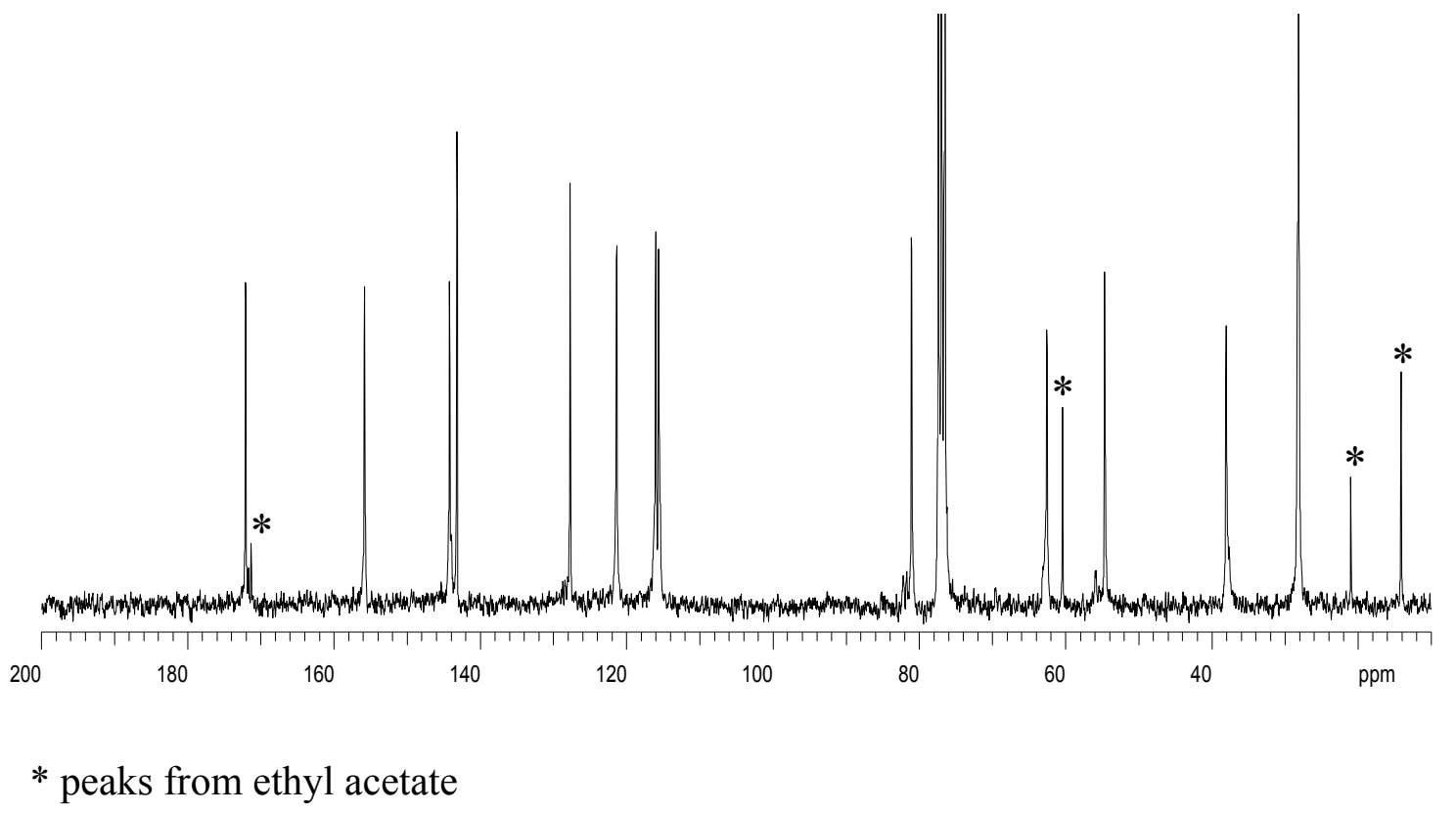




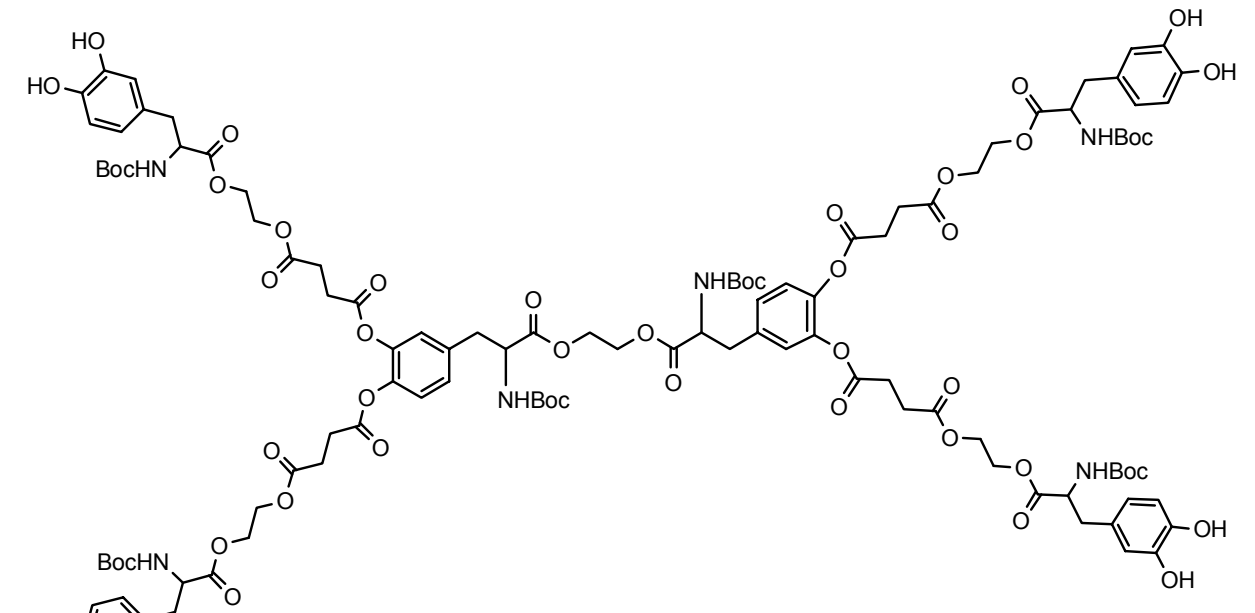

10

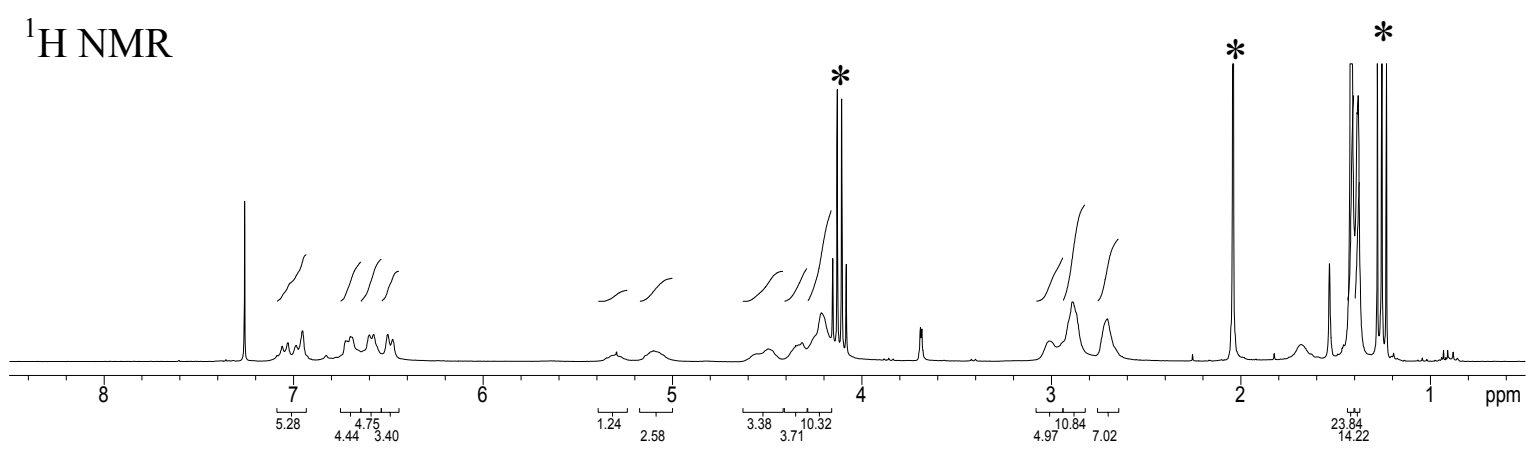

${ }^{13} \mathrm{C}$ NMR

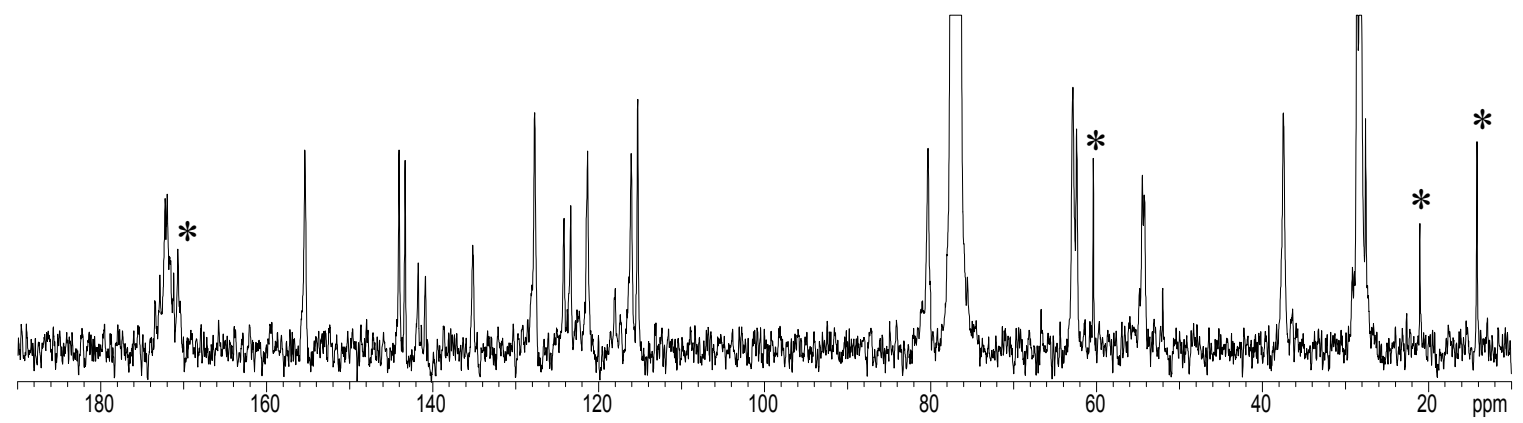

* peaks from ethyl acetate 


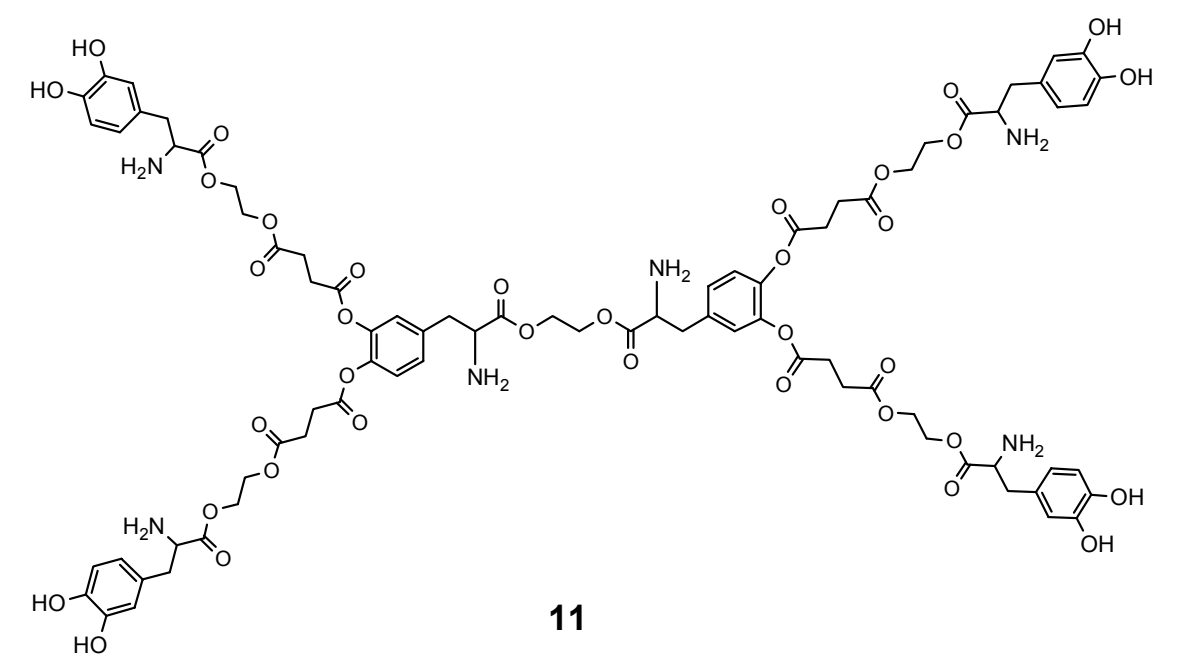

\section{${ }^{1} \mathrm{H}$ NMR}
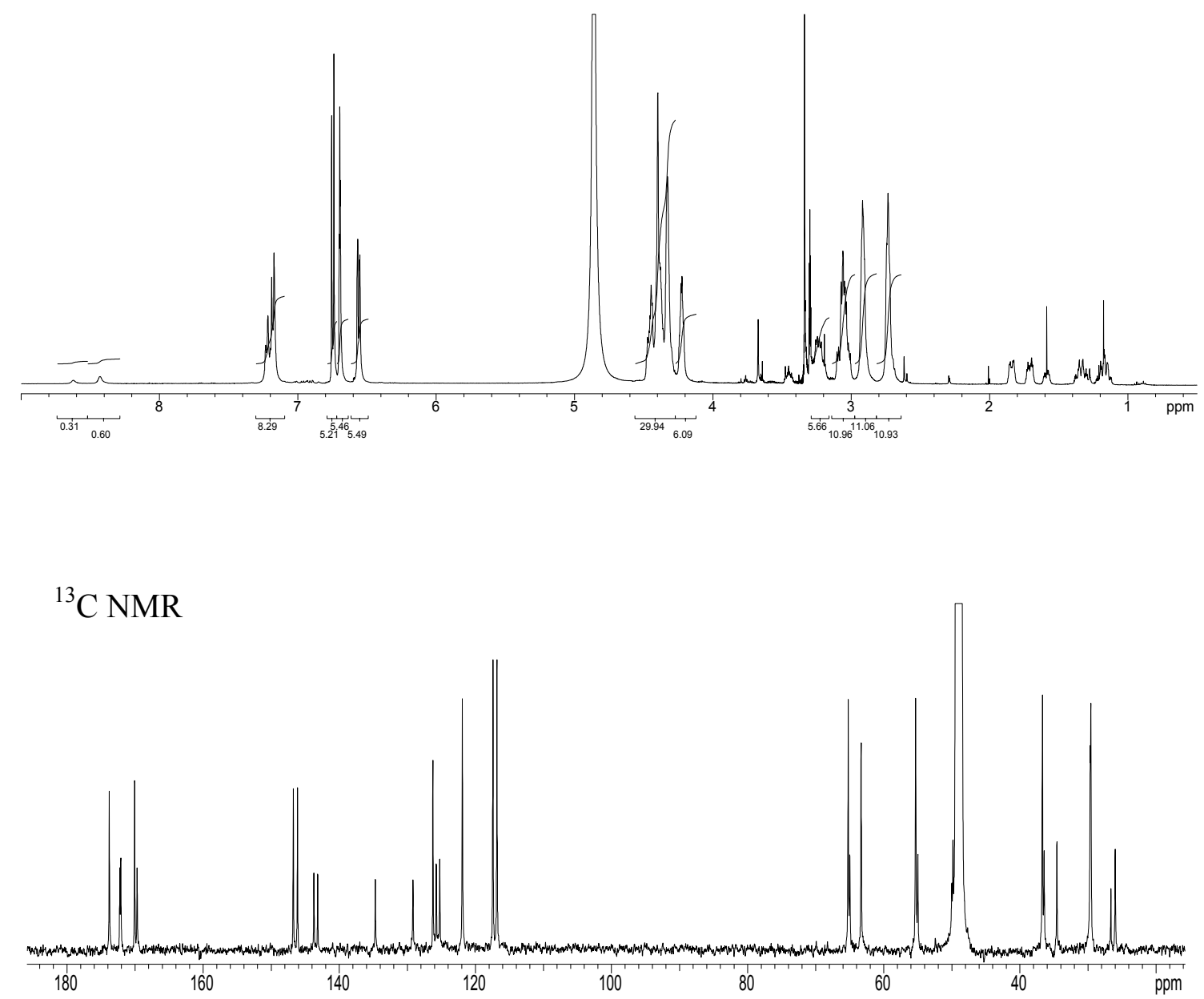

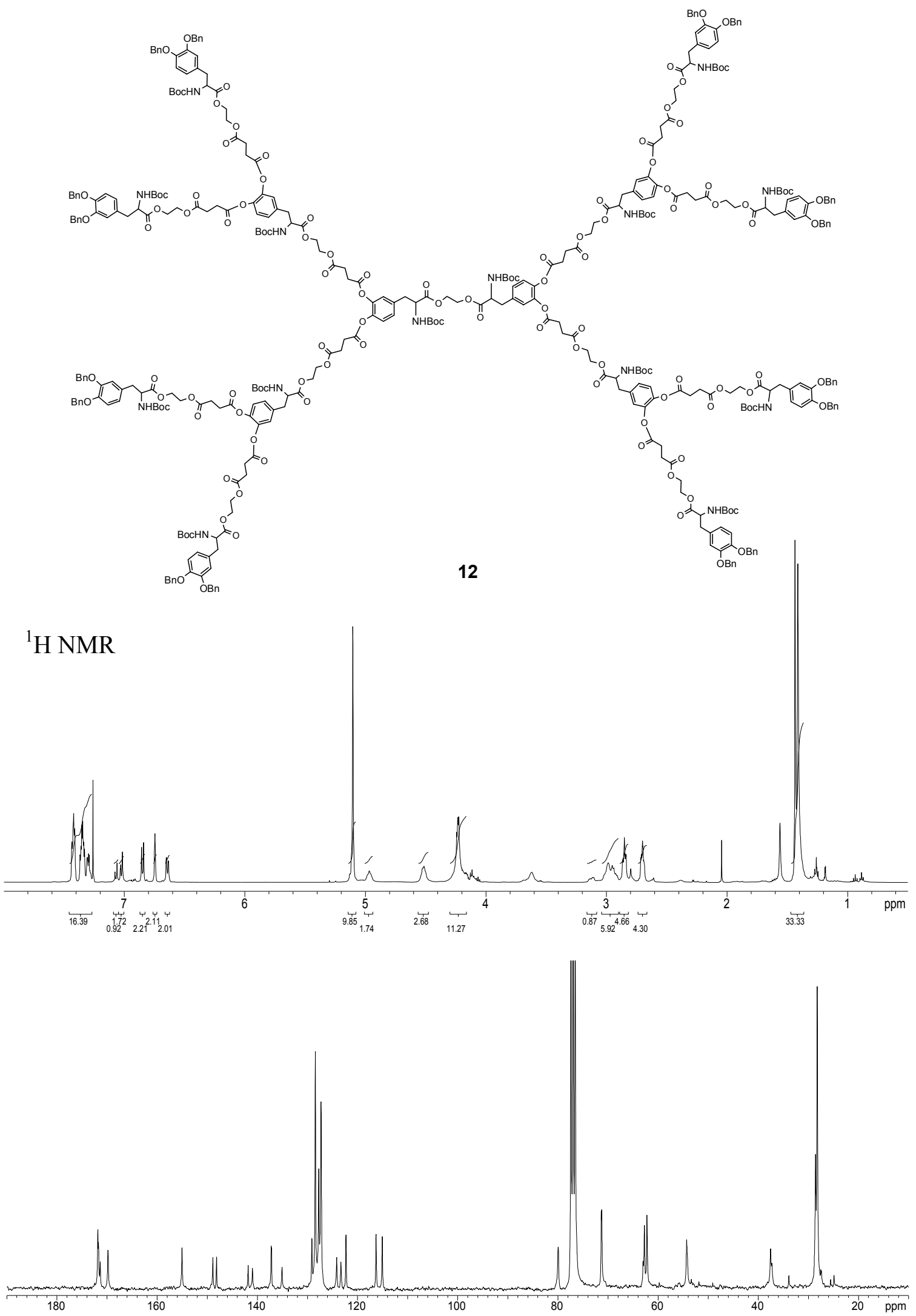

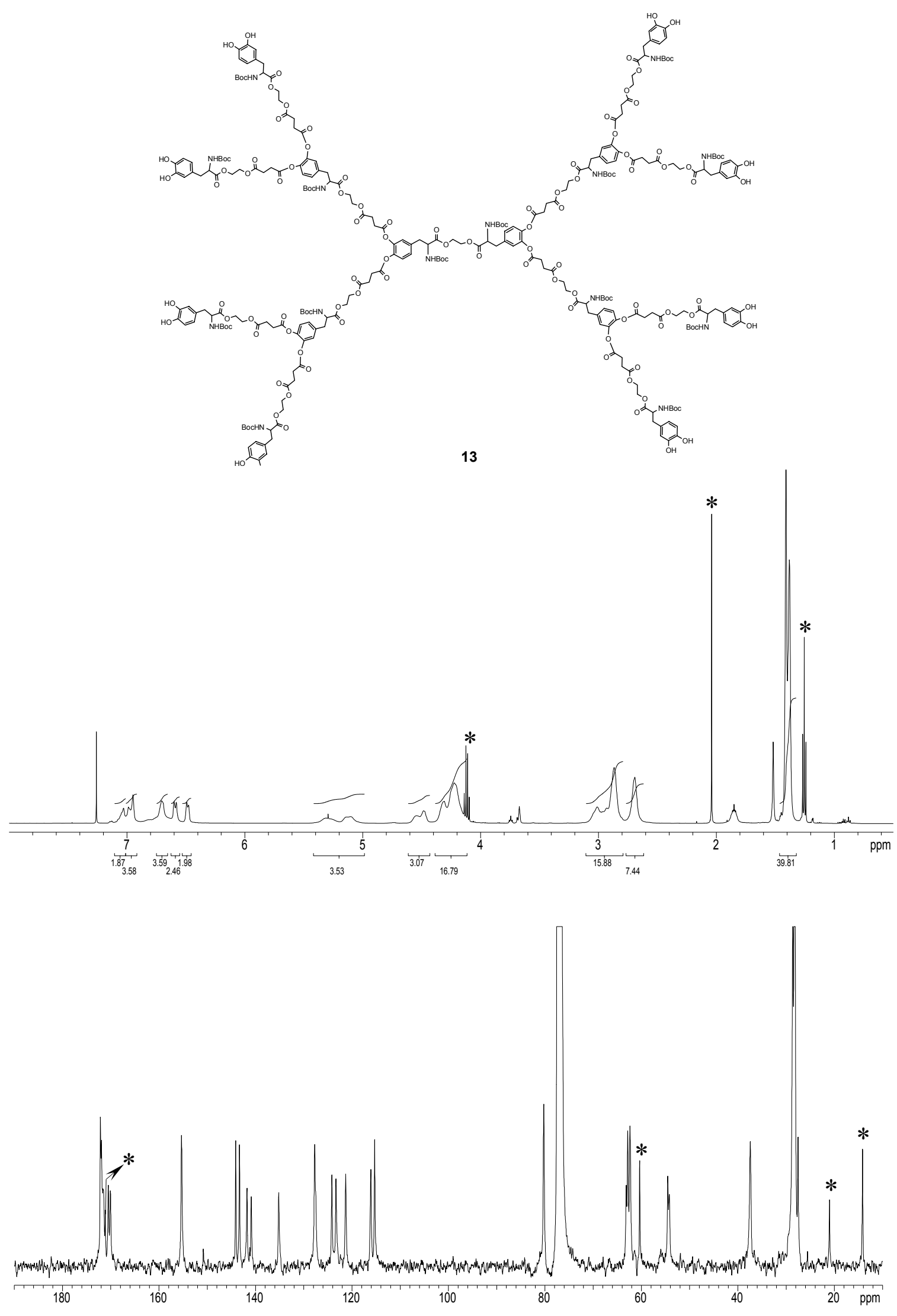

* peaks from ethyl acetate 


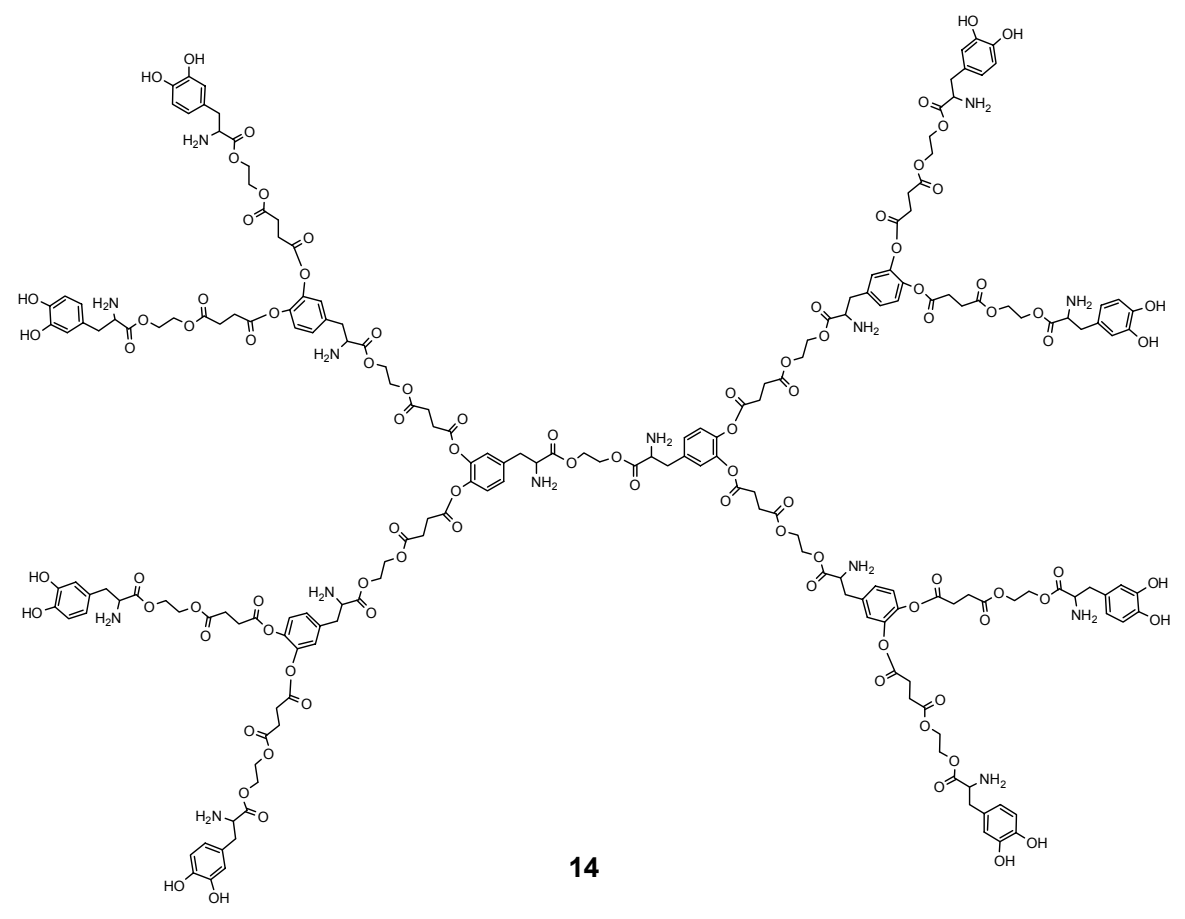

\section{${ }^{1} \mathrm{H}$ NMR}

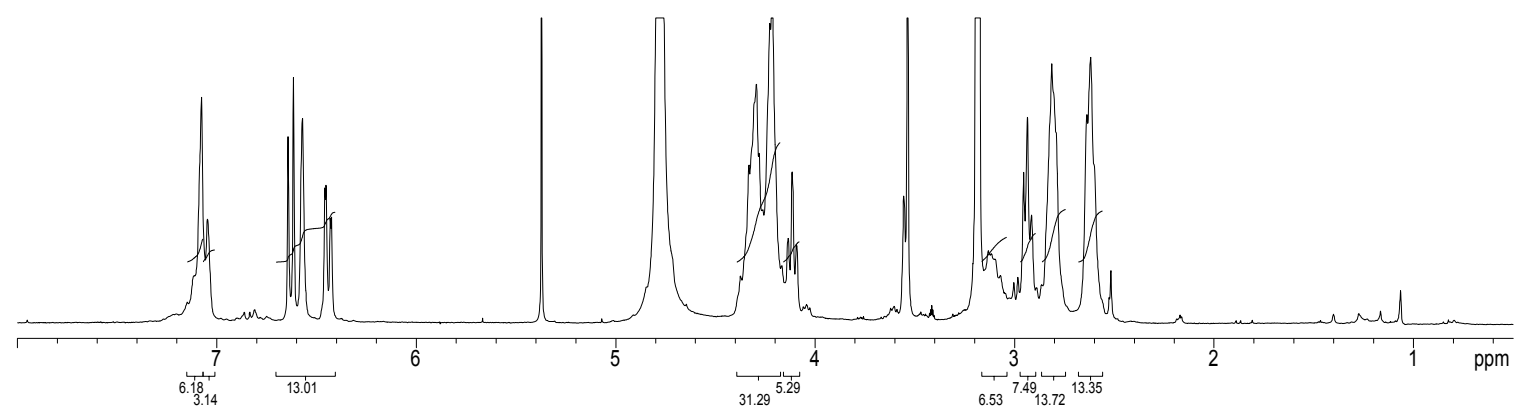

\section{${ }^{13} \mathrm{C}$ NMR}

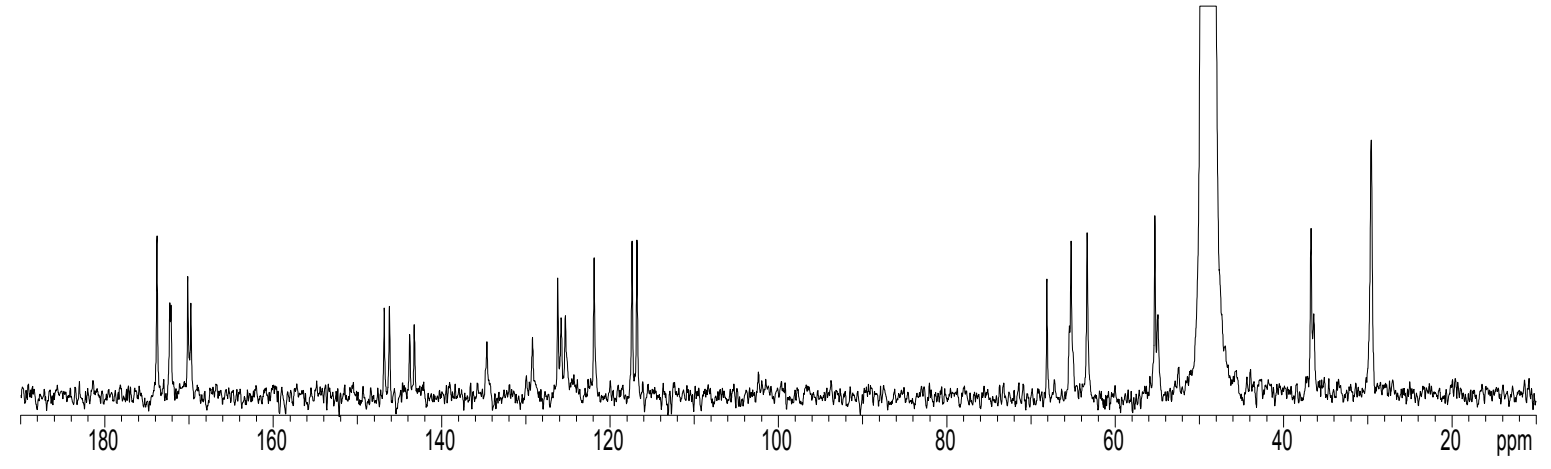



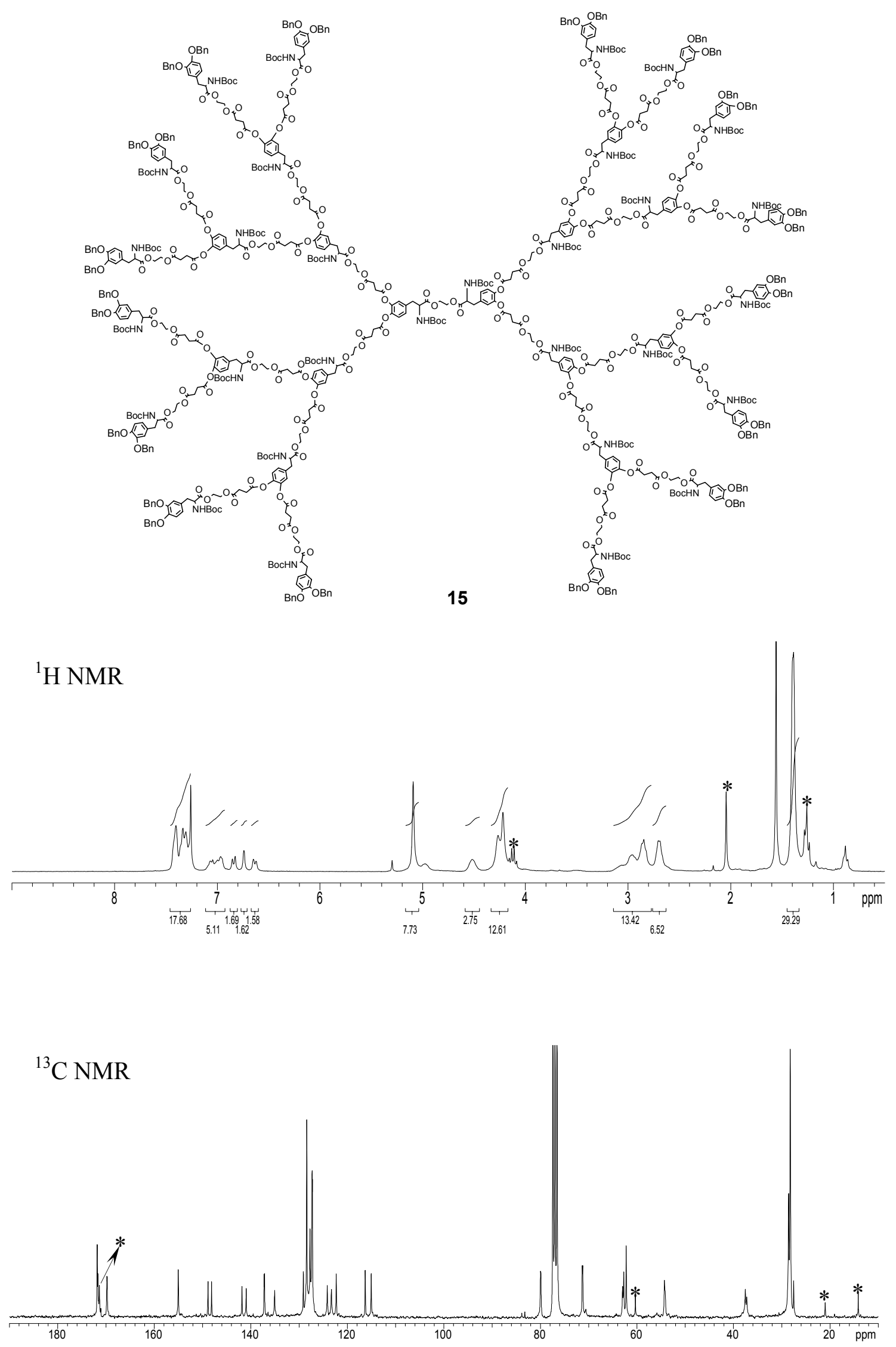

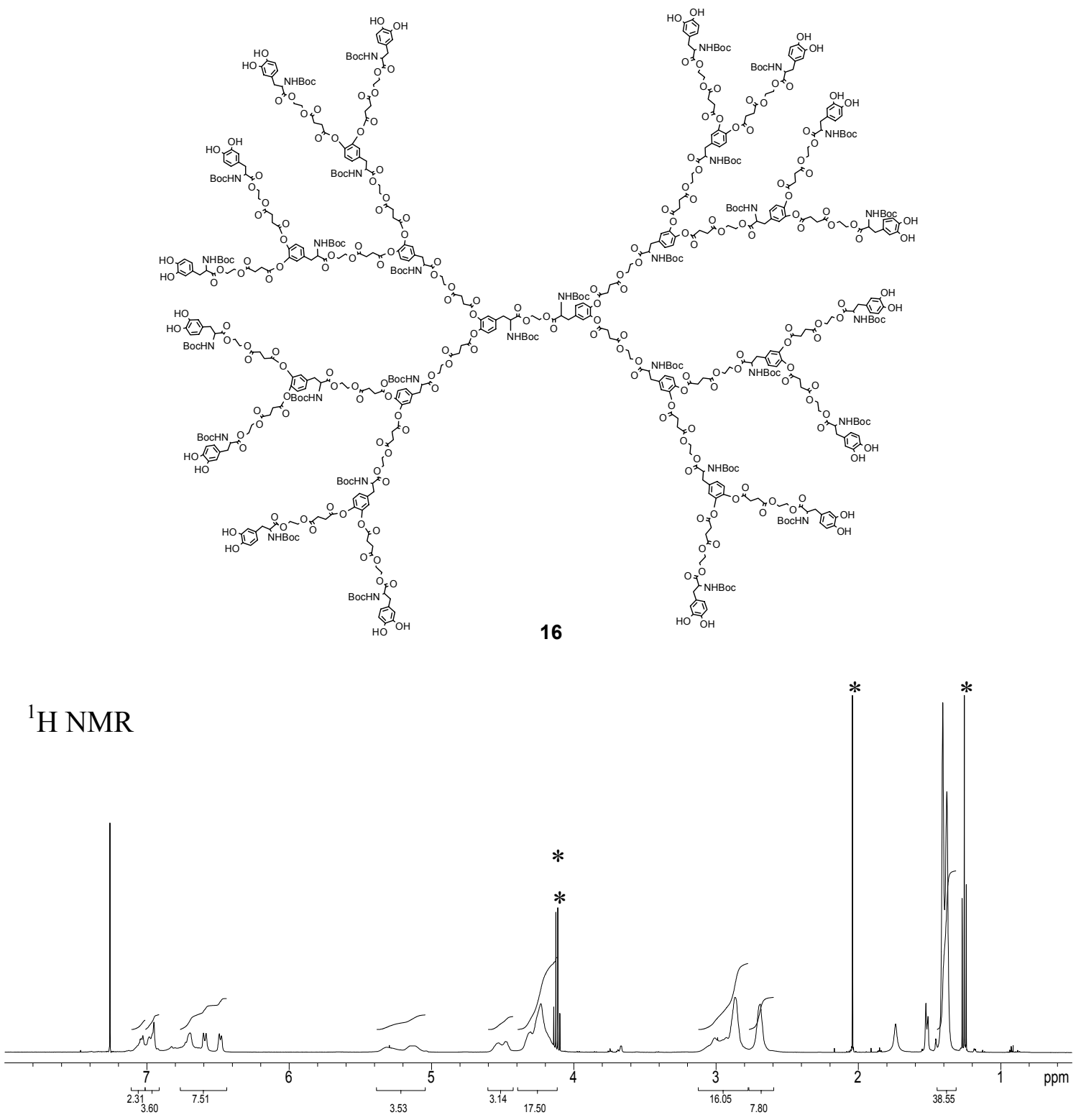

${ }^{13} \mathrm{C}$ NMR

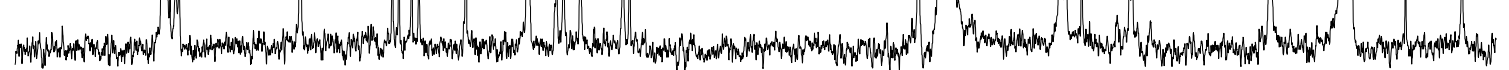

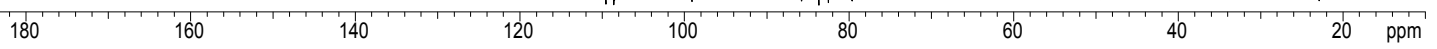



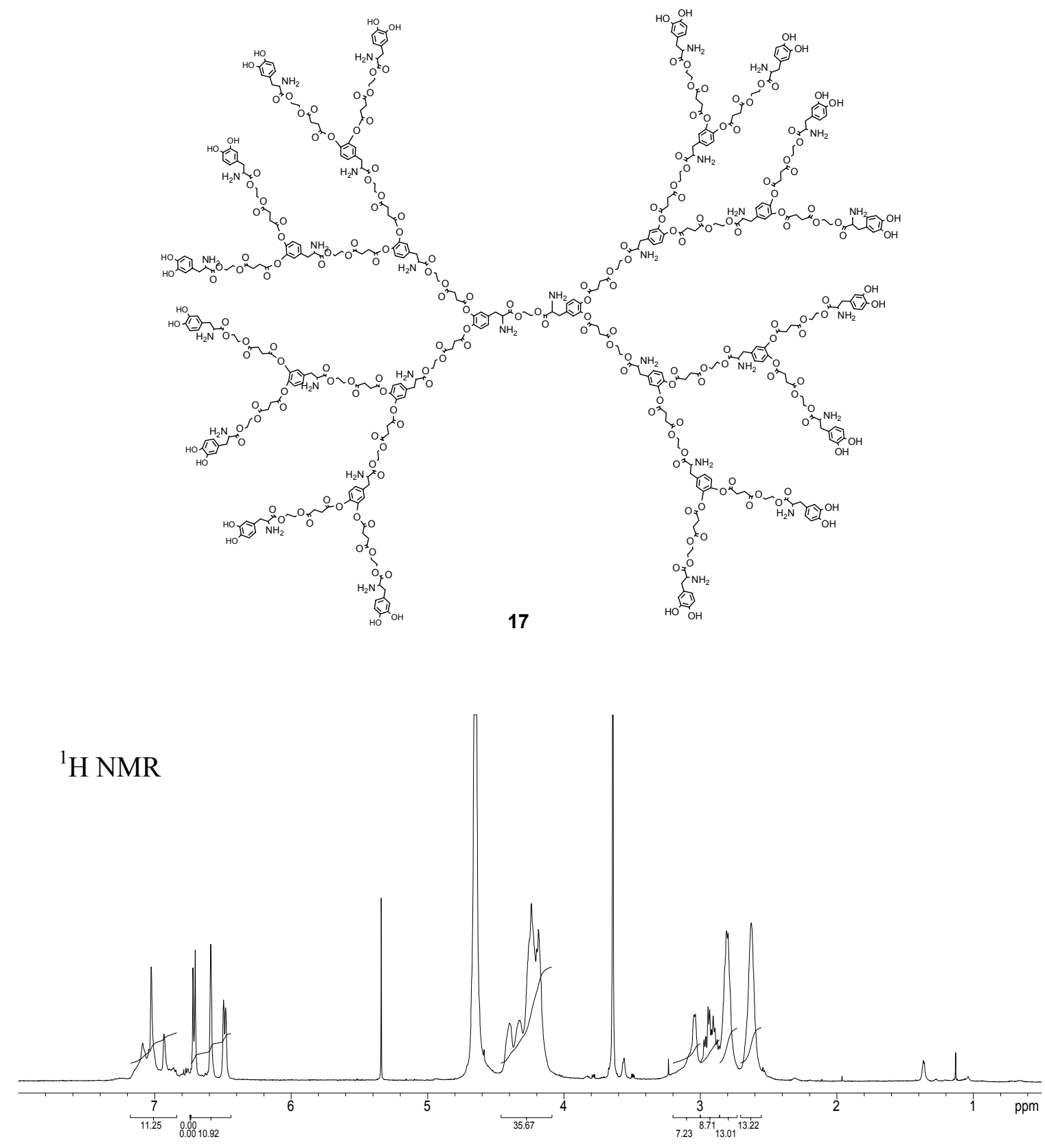

${ }^{13} \mathrm{C}$ NMR

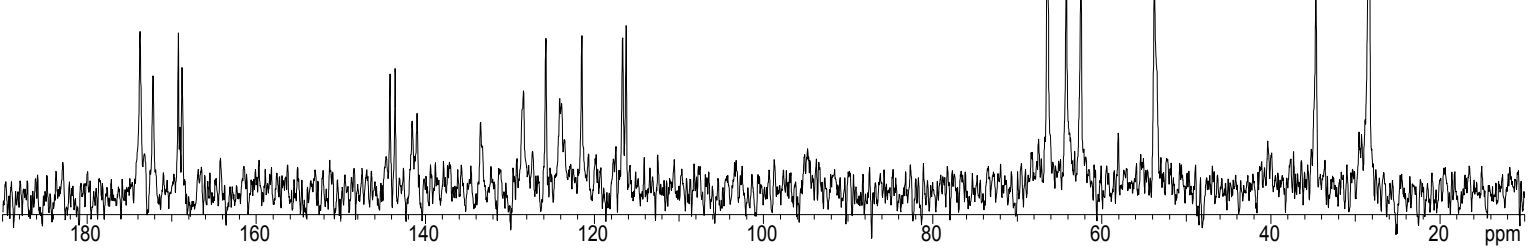




\section{UV-Vis Data on the Photostability of L-DOPA and G3 L-DOPA Dendrimer}

Both L-DOPA and G3 L-DOPA dendrimer were freshly dissolved in deionized water $(1 \mathrm{mg} / \mathrm{mL})$ for photostability study. L-DOPA solution turned black after a day because of the photo-oxidation; however, G3 L-DOPA dendrimer solution kept clear for more than several weeks. The dark L-DOPA solution has a distinct absorption around $400 \mathrm{~nm}$. The UV-Vis absorbances at $400 \mathrm{~nm}$ were measured for both L-DOPA and G3-L-DOPA dendrimer solutions for 5 days. The UV-Vis absorbance at $400 \mathrm{~nm}$ versus time (by day) was plotted shown in the following figure. It is clearly observed that the absorbance at $400 \mathrm{~nm}$ of L-DOPA solution was increasing dramatically per day. But the absorbance at $400 \mathrm{~nm}$ of G3 L-DOPA dendrimer solution changed very little over the time.

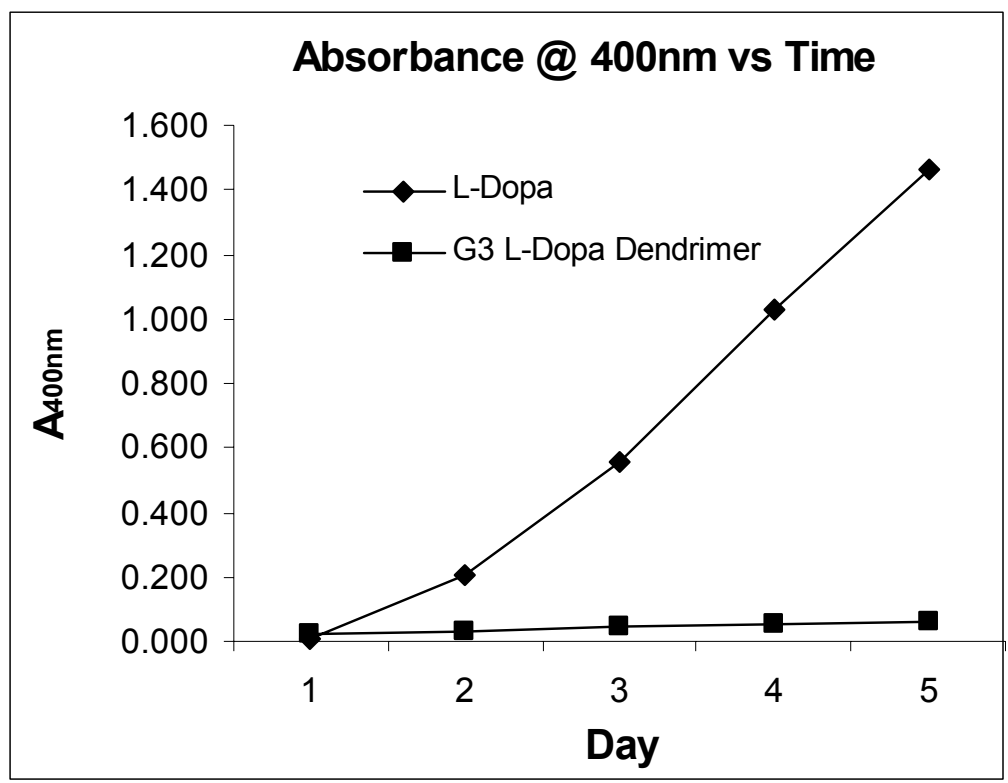




\section{HPLC Chromatograms of L-DOPA Dendrimers G0-G3}

All generations of L-DOPA dendrimers were analyzed by HPLC using a C18 column with water-acetonitrile bi-solvent gradient elution (starting with 19:1 ratio of water to acetonitrile and ending with $100 \%$ of acetonitrile) at a flow rate of $1.00 \mathrm{~mL} / \mathrm{min}$. The chromatogram of each generation L-DOPA dendrimer showed the final product has high purity for dendritic macromolecules.
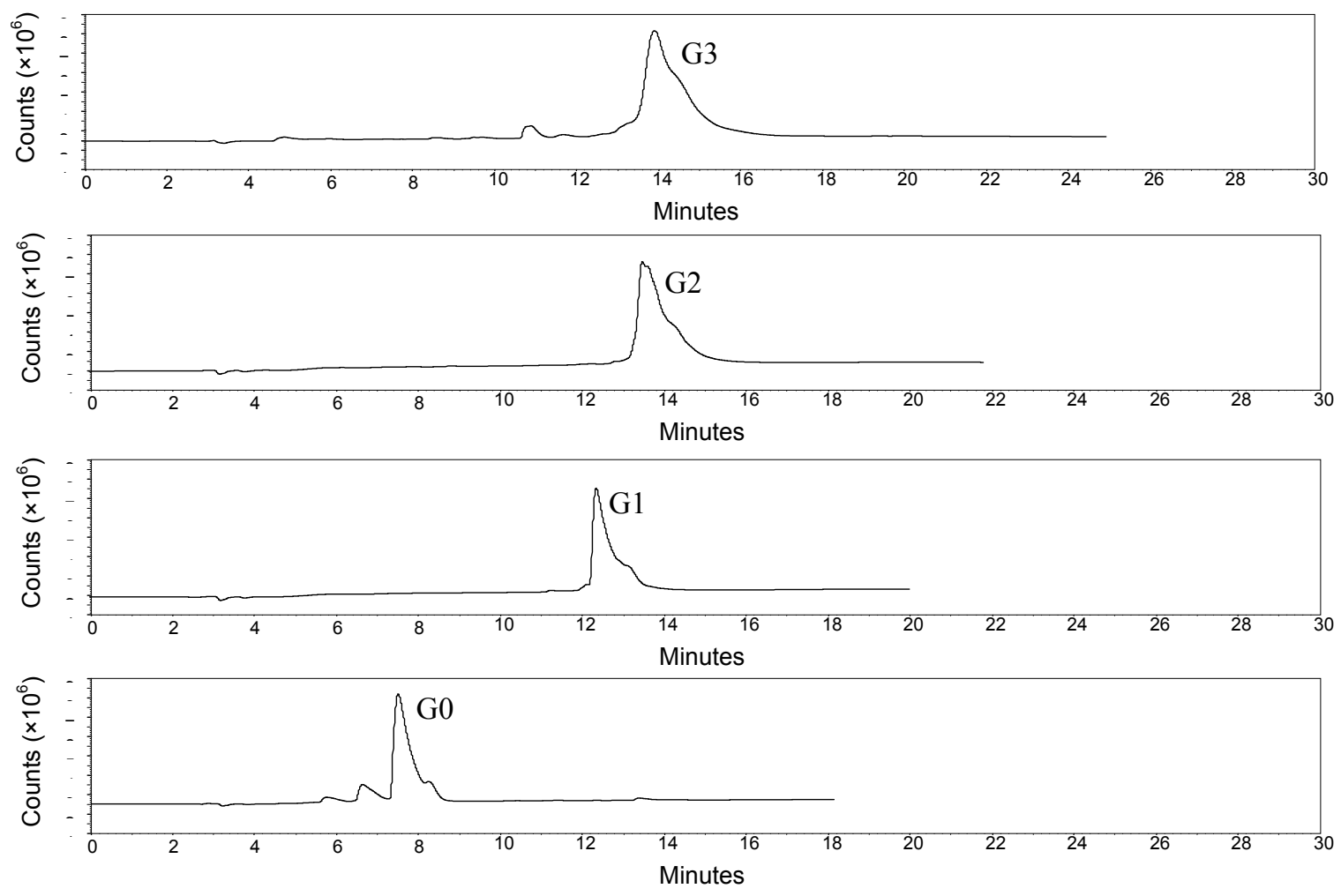


\section{NMR and HPLC Studies on the Degradation of L-DOPA Dendrimers}

The in vitro degradation (or hydrolysis) of novel dendritic L-DOPA prodrugs was studied using ${ }^{1} \mathrm{H}$ NMR and HPLC. The $3^{\text {rd }}$ generation dendrimer was dissolved in deionized water and the sample was monitored by HPLC for four days. The chromatograms acquired at the different time or days were shown as follows:

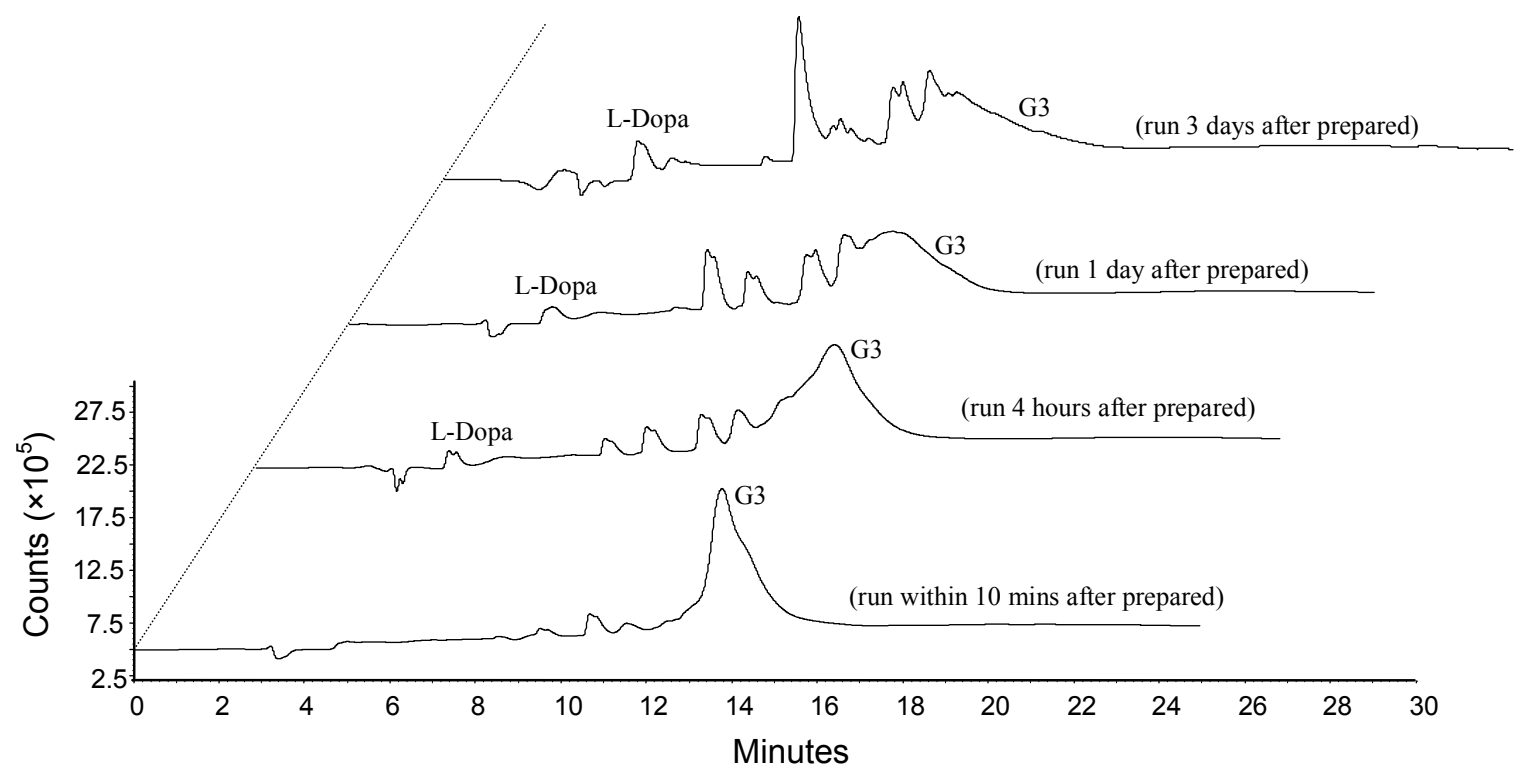

The degradation of the G3 dendrimer was clearly observed by HPLC even within half a day time. The degradation pattern with multiple intermediates formed and consumed over the time period of observation indicates that the degradation may undergo sequentially as expected from the dendritic architecture. The amount of L-DOPA released is gradually increased in the course of hydrolysis, which is also consistent with the sequential degradation hypothesis. Furthermore, the degradation of G1 dendritic prodrug was monitored for a couple of weeks by ${ }^{1} \mathrm{H}$ NMR under deuterated PBS $(\mathrm{pH}=7.5)$ condition at the room temperature. The ${ }^{1} \mathrm{H}$ NMR plots shown as follows demonstrated the degradation began instantly within half an hour. The NMR peak integration values of the L-DOPA released, the intermediates formed as well as the existing L-DOPA dendrimer 


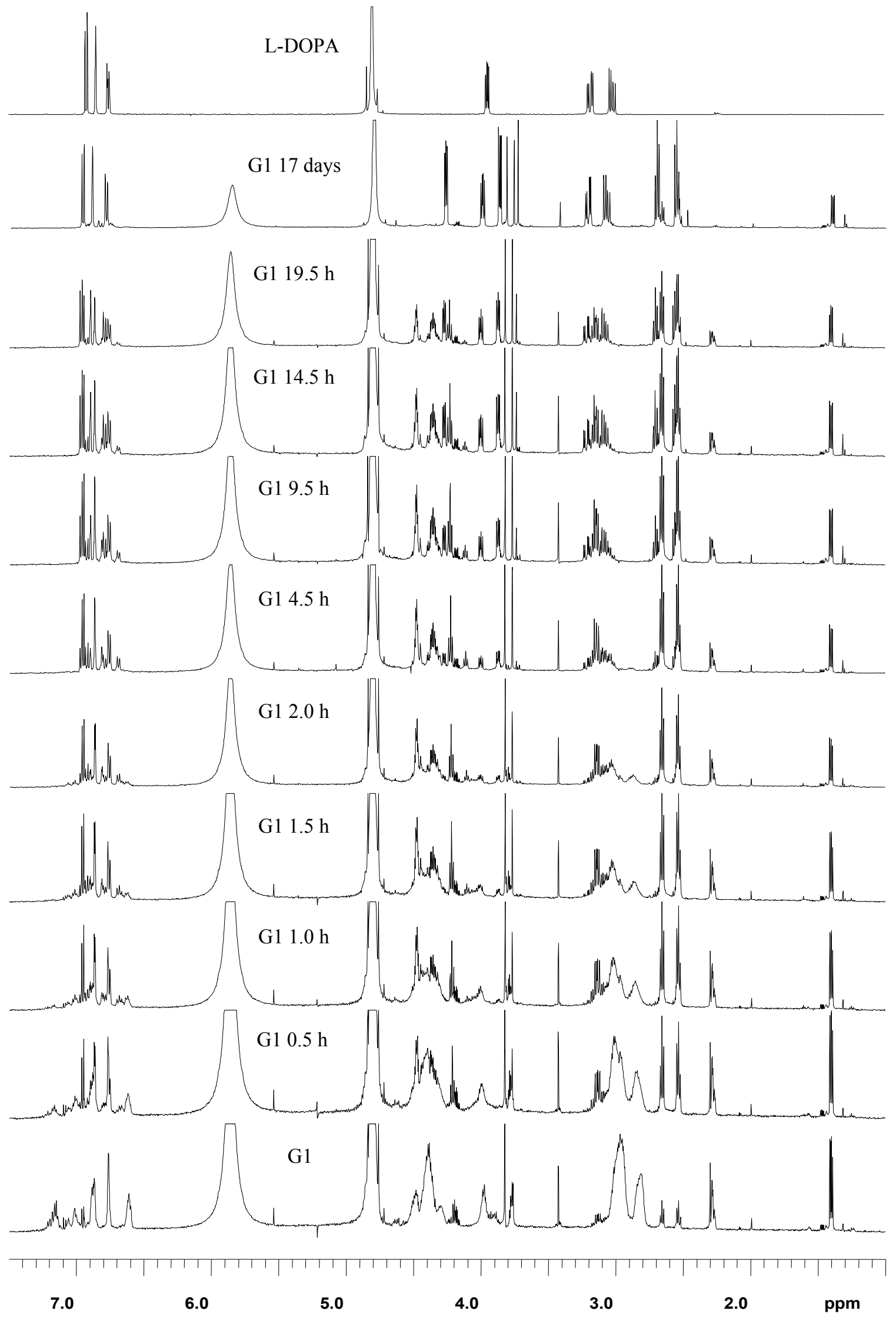




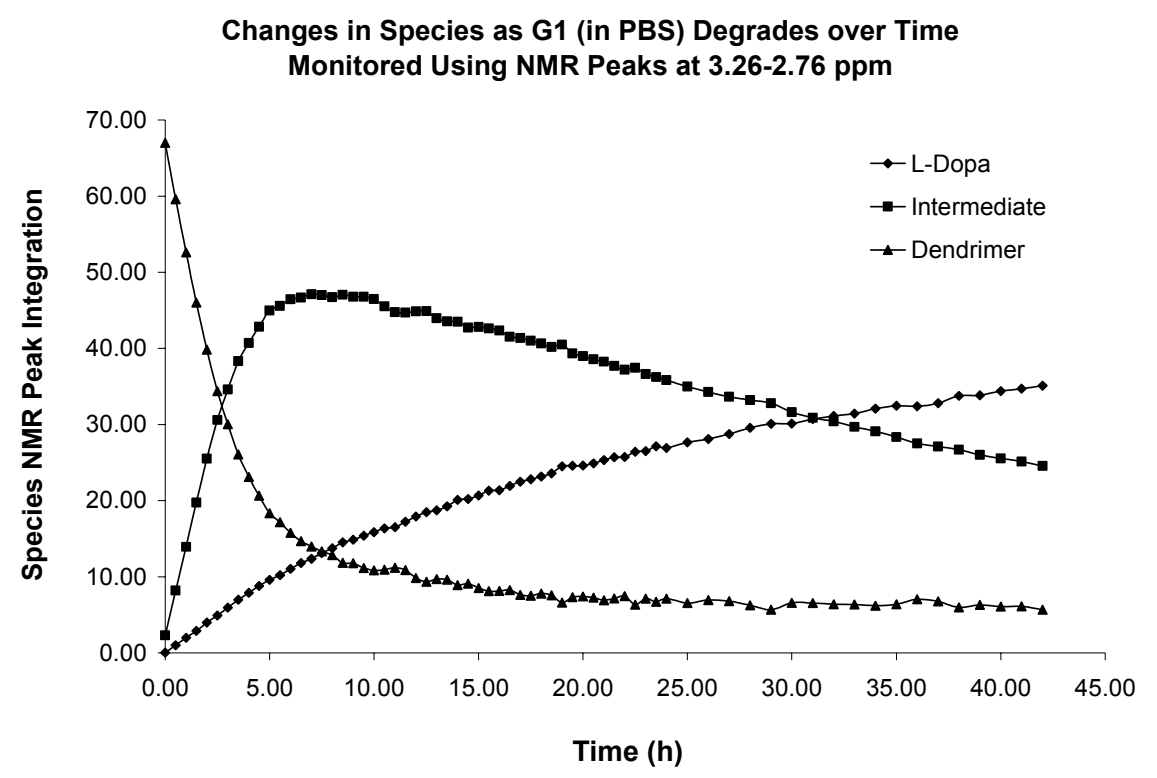

were used to represent the amount of each species in the system during degradation and plotted versus time, which provided the kinetic information of the degradation. The kinetic plot is clearly shown that L-DOPA G1 dendrimer was nearly consumed within 9.5 hours. Several intermediates (but NMR resonances were overlapped) were formed and consumed gradually at different time periods, and L-DOPA amount steadily increased during the entire process and eventually became the major component of the system after 40 hours. This study proved that the L-DOPA did release from the dendrimer sequentially. Same types of NMR experiments were also performed on the G2 dendrimer in the deionized water solution as well as the PBS solution (all solutions were made using deuterated reagents). Similar degradation trends were observed as in the G1 dendrimer system. Furthermore, the degradation rate of the G2 dendrimer was much slower in the deionized water solution than in the PBS solution. Studies at different $\mathrm{pH}$ conditions indicated that the degradation of L-DOPA dendrimers is a base-catalyzed hydrolysis process. Further detailed quantitative measurements of the L-DOPA released from the dendritic prodrugs will be done in the future using both NMR and HPLC. 